\title{
Arthropod IGF, relaxin and gonadulin, putative orthologs of Drosophila insulin-like peptides 6, 7 and 8, likely originated from an ancient gene triplication
}

\author{
Jan A Veenstra ${ }^{\text {Corresp. } 1}$ \\ 1 INCIA UMR 5287 CNRS, Université de Bordeaux, Pessac, France \\ Corresponding Author: Jan A Veenstra \\ Email address: jan-adrianus.veenstra@u-bordeaux.fr
}

Background. Insects have several genes coding for insulin-like peptides and they have been particularly well studied in Drosophila. Some of these hormones function as growth hormones and are produced by the fat body and the brain. These act through a typical insulin receptor tyrosine kinase. Two other Drosophila insulin-like hormones are either known or suspected to act through a G-protein coupled receptor. Although insulin-related peptides are known from other insect species, Drosophila insulin-like peptide 8, one that uses a G-protein coupled receptor, has so far only been identified from Drosophila and other flies. However, its receptor is widespread within arthropods and hence it should have orthologs. Such putative orthologs were recently identified in decapods and have been called gonadulins.

Methodology. In an effort to identify gonadulins in other arthropods public genome assemblies and shortread archives from insects and other arthropods were explored for the presence of genes and transcripts coding insulin-like peptides and their putative receptors.

Results. Gonadulins were detected in a number of arthropods. In those species for which transcriptome data from the gonads is available insect gonadulin genes are expressed in the ovaries and at least in some species also in the testes. In some insects differences in gonadulin expression in the ovary between actively reproducing and non-reproducing females differs more than 100-fold. Putative orthologs of Drosophila ilp 6 were also identified. In several non-Dipteran insects these peptides have C-terminally extensions that are alternatively spliced. The predicted peptides have been called arthropod insulin-like growth factors. In cockroaches, termites and stick insects genes coding for the arthropod insulin-like growth factors, gonadulin and relaxin, a third insulin-like peptide, are encoded by genes that are next to one another suggesting that they are the result of a local gene triplication. Such a close chromosomal association was also found for the arthropod insulin-like growth factor and gonadulin genes in spiders. Phylogenetic tree analysis of the typical insulin receptor tyrosine kinases from insects, decapods and chelicerates shows that the insulin signaling pathway evolved differently in these three groups. The Gprotein coupled receptors that are related to the Drosophila ilp 8 receptor similarly show significant differences between those groups.

Conclusion. A local gene triplication in an early ancestor likely yielded three genes coding gonadulin, arthropod insulin-like growth factor and relaxin. Orthologs of these genes are now commonly present in arthropods and almost certainly include the Drosophila insulin-like peptides 6, 7 and 8. 


\section{Arthropod IGF, Relaxin and Gonadulin, putative}

2 orthologs of Drosophila insulin-like peptides 6, 7 and

Jan A. Veenstra ${ }^{1}$,

${ }^{1}$ INCIA UMR 5287 CNRS, Université de Bordeaux, Bordeaux, Pessac, France

Corresponding Author:

Jan A. Veenstra ${ }^{1}$

INCIA UMR 5287 CNRS, Université de Bordeaux, allée Geoffroy St Hillaire, CS 50023, 33615

Pessac Cedex, France

Email address: jan-adrianus.veenstra@u-bordeaux.fr

\section{Abstract}

Background. Insects have several genes coding for insulin-like peptides and they have been particularly well studied in Drosophila. Some of these hormones function as growth hormones and are produced by the fat body and the brain. These act through a typical insulin receptor tyrosine kinase. Two other Drosophila insulin-like hormones are either known or suspected to act through a G-protein coupled receptor. Although insulin-related peptides are known from other insect species, Drosophila insulin-like peptide 8, one that uses a G-protein coupled receptor, has so far only been identified from Drosophila and other flies. However, its receptor is widespread within arthropods and hence it should have orthologs. Such putative orthologs were recently identified in decapods and have been called gonadulins.

Methodology. In an effort to identify gonadulins in other arthropods public genome assemblies and short-read archives from insects and other arthropods were explored for the presence of genes and transcripts coding insulin-like peptides and their putative receptors.

Results. Gonadulins were detected in a number of arthropods. In those species for which transcriptome data from the gonads is available insect gonadulin genes are expressed in the ovaries and at least in some species also in the testes. In some insects differences in gonadulin expression in the ovary between actively reproducing and non-reproducing females differs more than 100-fold. Putative orthologs of Drosophila ilp 6 were also identified. In several nonDipteran insects these peptides have C-terminally extensions that are alternatively spliced. The predicted peptides have been called arthropod insulin-like growth factors. In cockroaches, termites and stick insects genes coding for the arthropod insulin-like growth factors, gonadulin and relaxin, a third insulin-like peptide, are encoded by genes that are next to one another 
38 suggesting that they are the result of a local gene triplication. Such a close chromosomal association was also found for the arthropod insulin-like growth factor and gonadulin genes in spiders. Phylogenetic tree analysis of the typical insulin receptor tyrosine kinases from insects, decapods and chelicerates shows that the insulin signaling pathway evolved differently in these three groups. The G-protein coupled receptors that are related to the Drosophila ilp 8 receptor similarly show significant differences between those groups.

Conclusion. A local gene triplication in an early ancestor likely yielded three genes coding gonadulin, arthropod insulin-like growth factor and relaxin. Orthologs of these genes are now commonly present in arthropods and almost certainly include the Drosophila insulin-like peptides 6, 7 and 8.

\section{Introduction}

Insulin may well be the best studied and perhaps the best known hormone, due to its essential role in the regulation of glucose homeostasis and its effective and widespread use to treat diabetes. Insulin is related to a number of other hormones with different functions, such as insulin-like growth factors, relaxin and Ins3-5. One of the interesting aspects of these hormones is their use of two structurally very different receptors, receptor tyrosine kinases (RTKs) and leucine-rich repeat G-protein coupled receptors (LGRs). Thus, whereas insulin and insulin-like growth factors (IGFs) act through an RTK, relaxin and Ins3 use an LGR for signal transduction. An intriguing question remains as to how this switch was made from one type of receptor to another, or alternatively whether the ancestral insulin used perhaps both types of receptors and during evolution its descendants became specific ligands for only one of the two receptors. Like other hormones and neuropeptides, insulin was already present in the ancestral bilaterian that gave rise to both protostomes and deuterostomes. The first indication that an insulin-like peptide (ilp) might exist in protostomes was the observation that insulin enhances cell differentiation in cultured Drosophila cells (Seecof \& Dewhurst, 1974). The identification of one ilp in the silkworm Bombyx mori that can break diapause (Nagasawa et al., 1984, 1986) and another one in neuroendocrine cells known to produce a growth hormone in the pond snail Lymnaea stagnalis (Smit et al., 1988) reinforced the hypothesis that insulin may function as growth hormones in protostomes. Since then a large variety of invertebrates has yielded a still larger variety of ilps (e.g. Murphy \& Hu, 2013; Mizoguchi \& Okamoto, 2013; Nässel \& Vanden Broeck, 2016; Yu, Han \& Liu, 2020). 
71 In insects the ilps of Drosophila and the silkworm Bombyx mori have been extensively studied

72 and these hormones are best known in fruit fly due to the genetic power that can be employed in

73 this species. There are eight ilp genes in Drosophila melanogaster, which are referred to as

74 Drosophila ilps 1-8. Drosophila ilps 1, 2, 3 and 5 are co-expressed in a single cell type of

75

76

77 neuroendocrine cells of the brain (Brogiolo et al., 2001; Grönke et al., 2010). Of these ilp 2 seems to be the most important and it also seems to be expressed exclusively or predominantly in these brain neuroendocrine cells. Drosophila ilps 3 and 5 are also expressed in other tissues, e.g. ilp 3 is expressed in midgut muscle of both larvae and adults where its expression stimulates midgut growth in response to feeding (O’Brien et al., 2011). Drosophila ilp 1 has been shown to be expressed in the brain neuroendocrine cells, but its expression is largely limited to stages when the animal does not feed, i.e. metamorphosis and diapause (Liu et al., 2016). The expression of dilp 4 seems limited to the embryonic stage, while ilp 6 is expressed predominantly if not exclusively by the fat body (Slaidina et al., 2009; Okamoto et al., 2009b). All these ilps are believed to activate the single Drosophila insulin RTK, while Drosophila ilps 7 and 8 are either known (ilp 8) or suspected (ilp 7) to activate Drosophila LGRs 3 and 4 respectively (Vallejo et al., 2015; Gontijo \& Garelli, 2018; Veenstra et al., 2012). Drosophila ilp 7 is expressed by neurons in the abdominal neuromeres in a sex specific manner (Miguel-Aliaga, Thor \& Gould, 2008; Yang et al., 2008; Castellanos, Tang \& Allan, 2013), while ilp 8 is expressed by the imaginal disks as well as the ovary and testes as shown by flyatlas (Gontijo \& Garelli, 2018; Liao \& Nässel, 2020).

The primary amino acid sequences of the Drosophila ilps vary considerably and this is also the case in other arthropod species that have multiple genes coding insulin-related peptides. There is not only large sequence variability within a species, but also between species. Only when species are relatively closely related is it possible to reliably identify orthologous genes in different species. However, while in most insects the A- and B-chains have thus quite variable amino acid sequences, this not the case for orthologs of Drosophila ilp 7. The strong conservation of the primary amino acid sequence of these peptides allows for easy identification of its orthologs, not only in other insect species, but also in other protostomes like various mollusks and even in some deuterostomes (Veenstra et al., 2012). The strongly conserved primary amino acid sequence of these peptides suggests that it interacts with another receptor than the other ilps, perhaps in addition to the RTK. As some ilps act through a G-protein coupled receptor (GPCR), it seemed a distinct possibility that Drosophila ilp 7 and their orthologs might also stimulate a GPCR. Interestingly, genes coding LGR4 and its orthologs are present in the same genomes as those that 
104 have genes coding orthologs of Drosophila ilp 7. This holds not only for insects, but also other

105 arthropods, mollusks and even some basal deuterostomes. Every genome that has a Drosophila

106 ilp 7 ortholog also has a LGR4 ortholog and vice versa (Veenstra et al., 2012; Veenstra, 2014,

107 2019). Furthermore, LGR3 and LGR4 are holomologs of vertebrate LGRs that use ilps as ligands.

108 This means that the ligands for the LGR4s must be the Drosophila ilp 7 orthologs. Since these

109 peptides are so different from the typical insect neuroendocrine insulins, it made sense to give it a

110 different name. Earlier work on Drosophila suggested that it might have a role similar to relaxin

111 in vertebrates (Yang et al., 2008) and since LGR4 is an ortholog of the relaxin receptor (Veenstra,

112 2014), has also been called relaxin, but it might be better to call them arthropod or invertebrate

113 relaxin.

114 Drosophila ilp 8 is another ilp (for review see Gontijo \& Garelli, 2018) that acts through a

115 leucine-rich repeat GPCR, LGR3 (Garelli et al., 2015; Vallejo et al., 2015; Colombani et al.,

116 2015). However, whereas Drosophila ilp 7 orthologs have well conserved primary amino acid

117 sequences, this is not the case for Drosophila ilp 8. Indeed, if it were not for the common

118 presence of LGR3 orthologs in insect and other arthropod genomes one might believe that this

119 peptide hormone evolved within the higher flies and is absent from other insects. The imaginal

120 disks in Drosophila produce and release ilp 8 as long as they develop and also when they get

121 damaged. When it is no longer released this is used by the brain as a signal to initiate

122 metamorphosis (Garelli et al., 2012; Colombani, Andersen \& Léopold, 2012; Jaszczak et al.,

123 2016). Drosophila ilp 8 is furthermore produced by the testes and ovaries (Liao \& Nässel, 2020)

124 and since imaginal disks are only present in holometabolous insects, it is tempting to speculate

125 that the gonads are the original site of expression of orthologs of this peptide. I had previously

126 suggested that the crustacean androgenic insulin-like peptide that stimulates premature sexual

127 maturation in male crustaceans and can induce sex reversal in females, might be an ortholog of

128 Drosophila ilp 8 (Veenstra, 2016b). However, more recently a fourth type of ilp was identified in

129 two decapod species, that seem to be structurally more similar to Drosophila ilp 8 than the

130 androgenic insulin-like peptides (Chandler et al., 2017). It has now been shown that these

131 peptides, which have been called gonadulins, are generally present in decapods and commonly

132 expressed by the gonads (Veenstra, 2020). Since gonadulins might be orthologs of Drosophila ilp

1338 (Veenstra, 2020), it seemed worthwhile to look for this hormone in other arthropods. Analysis

134 of arthropod genome and transcriptome sequences revealed that such peptides are not limited to

135 decapods but are also present in insects as well as chelicerates. 
136 During this analysis interesting new details of the putative orthologs of Drosophila ilp 6 were

137 also encountered as well as evidence suggesting that the putative orthologs of Drosophila ilps 6,

1387 and 8 arose from an ancestral gene triplication.

\section{Materials \& Methods}

142 The sratoolkit (https://trace.ncbi.nlm.nih.gov/Traces/sra/sra.cgi?view=software) in combination 143 with Trinity (Grabherr et al., 2011) was used in the search for transcripts encoding peptides that 144 might be somewhat similar to insulin in insect gonad transcriptome short read archives (SRAs).

145 The method consisted of using the tblastn_vdb command from the sratoolkit to recover individual 146 reads from transcriptome SRAs that show possible sequence homology with insulin-like 147 molecules. Since insulin-like peptides have highly variable sequences the command is run with 148 the -seg no and -evalue 100 options. Reads that are identified are then collected using the vdbdump command from the sratoolkit. The total number of reads recovered is much smaller than those typically present in an SRA and this allows one to use Trinity on a normal desktop

151 computer to make a mini-transcriptome of those reads. This transcriptome is than searched using 152 the BLAST+ program (ftp://ftp.ncbi.nlm.nih.gov/blast/executables/blast+l) for possible insulin 153 transcripts. This first round usually yields numerous false positives and perhaps a few partial 154 transcripts that look interesting. These promising but partial transcripts are then used as query 155 using the blastn_vdb command from the sratoolkit on the same SRAs and reads are collected anew and Trinity is used to make another transcriptome that is again queried for the presence of

157 insulin-like transcripts. In order to obtain complete transcript the blastn_vdb search may need to

158 be repeated several times. Alternatively genes coding such transcripts were identified in genome 159 assemblies using the BLAST+ program and Artemis (Rutherford et al., 2000). Once such 160 transcripts had been found, it was often possible to find orthologs from related species. For 161 example, once the honeybee gonadulin was found, it was much easier to find it in other 162 Hymenoptera. The same methods were used to identify relaxin and C-terminally extended ilps, 163 which have much better conserved primary amino acid sequences and consequently are more 164 easily identified, as well as their putative receptors. Whenever possible all sequences were 165 confirmed in both genome assemblies and in transcriptome SRAs. In many cases transcripts for

166 the various ilps and receptors were already present in genbank, although they were not always 167 correctly identified. All these sequences are listed in Suppl. Spreadsheet 1. 
168 Expression was estimated by counting how many RNAseq reads in each SRA contained coding

169 sequence for each of the genes. In order to avoid untranslated sequences of the complete

170 transcripts, that sometimes share homologous stretches with transcripts from other genes and can

171 cause false positives, only the coding sequences were used as query in the blastn_vdb command

172 from the sratoolkit. This yielded the blue numbers in Suppl. Spreadsheet 2. In order to more

173 easily compare the different SRAs these numbers were then expressed as per million spots in

174 each particular SRA. These are the bold black numbers in Suppl. Spreadsheet 2.

175 For the expression of alternative aIGF (arthropod insulin-like growth factor) splice forms reads

176 for each splice variant were first separately identified. Unique identifiers in these two sets were

177 determined to obtain the total number of reads for aIGF. Those identifiers that were present in the

178 initial counts for both splice forms were counted separately and subtracted from the initial counts

179 of the two splice variants to obtain the number of reads specific for each isoform.

180 The various SRAs that were used are listed in the supplementary pdf file and were downloaded

181 from https://www.ncbi.nlm.nih.gov/sra/. The following genome assemblies were also analyzed:

182 Aedes aegypti (Matthews et al., 2018), Blattella germanica (Harrison et al., 2018), Bombyx mori

183 (Kawamoto et al., 2019), Galleria melonella (Lange et al., 2018), Glossina morsitans (Attardo et

184 al., 2019), Hermetia illucens (Zhan et al., 2020), Latrodectus hesperus

185 (https://www.ncbi.nlm.nih.gov/genome/?term=Latrodectus+hesperus), Mesobuthus martensii

186 (Cao et al., 2013), Oncopeltus fasciatus (Panfilio et al., 2019), Parasteatoda tepidariorum

187 (Schwager et al., 2017), Pardosa pseudoannulata (Yu et al., 2019), Periplaneta americana (Li et

188 al., 2018), Stegodyphus dumicola (Liu et al., 2019), Tetranychus urticae (Grbić et al., 2011),

189 Timema cristinae (Riesch et al., 2017), Tribolium castaneum (Herndon et al., 2020) and

190 Zootermopsis nevadensis (Terrapon et al., 2014). All genomes were downloaded from

191 https://www.ncbi.nlm.nih.gov/genome/.

192 
193

194 For the phylogenetic tree of the insulin RTKs sequences were aligned with clustal omega
195 (Sievers et al., 2011). Using Seaview (Gouy, Guindon \& Gascuel, 2010) only well aligned

195

196

197

198

199

200

201

202

203

204

205

206

207

208

209

210

211

212

213

214

215

216

217

218

219

220

221

222

\section{Phylogenetic and sequence similarity trees} sequences were retained and saved as a fasta file. Fasttree2 (Price et al., 2010) was then used to produce a phylogenetic tree using the .FastTreeDbl command with the following options: -spr 4 mlacc 2 -slownni. The phylogenetic GPCR tree was constructed in the same way using only the transmembrane regions.

The amino acid sequences of arthropod ilps are not well conserved and hence one can not make phylogenetic trees, as it is impossible to know which amino acid residues can be reliably aligned apart from the cysteines. Even the latter can cause problems when the spacing between is not the same in different peptides. To compare the different ilps an unbiased method is needed. For this clustal omega was used to align the complete precursor sequences and even though visual inspection with Seaview reveals very poor alignments, the alignment was not changed but saved as a fasta file and Fasttree was used with the same parameters as above to construct trees. Although such trees are not phylogenetic trees they do allow for an unbiased comparison of the various sequences. The trees so produced have been called sequence similarity trees. Note that the branch probabilities of such trees give useful information as to how reliable the grouping of the various ilp precursors is.

\section{Prediction of prepropeptides processing}

Signal peptides were predicted using signal P-5.0 (Almagro Armenteros et al., 2019). No attempts were made to predict convertase cleavage sites in the gonadulin and aIGF precursors. Both of these putative hormones are likely not made by neuroendocrine cells. This implies that these hormones may not be exposed to neuroendocrine convertases and hence rules that describe how these convertases might cleave would not be applicable.

\section{Results}

\section{Gonadulin-like peptides are present in many arthropods}

Peptides that share the typical location of six cysteine residues with insulin but are insufficiently similar to known insect ilps to be easily recognized as such, were identified in a large number of 
223 arthropods. Their sequences differ not only from other ilps, but are also very variable between

224 them. As a consequence they are difficult to find in genome assemblies, unless a sequence from a

225 not too distantly related species is available. This explains why searches were most successful

226 when done in ovary and/or testes transcriptomes. Putative gonadulin orthologs were identified not

227 only in insects, but also in several chelicerates, notably spiders, a spider mite and scorpions. A

228 list of gonadulin propeptides in representative species is given in Figure 1 and additional

229 sequences are provided in Suppl. Spreadsheet 1. It is evident that although these peptides have

230 been given the same name, their sequences diverge even more than the neuroendocrine arthropod

231 insulins. When constructing a sequence similarity tree from the insect ilps the gonadulins are well

232 separated from the relaxins and the other insect ilps. Interestingly even the insulins and aIGFs are

233 reasonably well separated, except for the precursors from highly evolved flies (Drosophila and

234 Glossina) and the head louse (Fig. 2). When this is repeated on sequences from a set of arthropod

235 ilps, the gonadulins are once again well separated from the other insulin related peptides (Fig. 3,

236 Fig. S1).

237 Publicly available transcriptomes were used to explore in which tissues they are expressed. By

238 nature such data is imperfect, as these transcriptomes were not made to answer the question

239 where gonadulin, other insulin-related peptides or their putative receptors are expressed and

240 hence such data is limited. Some of the more salient examples are illustrated in Table 1. In

241 honeybees the ovaries of virgin queens do not express significant amounts of gonadulin, but those

242 of egg-laying queens produce it in large quantities. In a single queen bumblebee larva

243 transcriptome the gonadulin reads are at least 15 times more numerous than those in the three

244 transcriptomes each for male and worker larvae (Suppl. Spreadsheet 2). In the tsetse fly Glossina

245 morsitans the gene is strongly expressed in ovaries of non-pregnant females, i.e. those that

246 mature an egg, and hardly at all in pregnant/lactating females when egg maturation is arrested. In

247 the bugs Rhodnius prolixus and Oncopeltus fasciatus the ovaries also express this gene, as do

248 ovaries and testes of the stick insect Timema cristinae, while short read archives of unfecundated

249 eggs from Blattella germanica similarly contain large amounts of gonadulin reads. In the termite

250 Zootermopsis nevadensis, gonadulin reads are abundant in reproducing females but rare or absent

251 in alate females or reproducing males. The gene is also expressed in the testis of the American

252 cockroach and possibly in the ovary as well, since it can be detected in whole body

253 transcriptomes from females (Suppl. Spreadsheet 2). However, as in decapods (Veenstra, 2020),

254 in insects gonadulin expression is not limited to the gonads (Table 1; Suppl. Spreadsheet 2). In

255 the spider Parasteatoda tepidariorum ovary expression of gonadulin varied significantly between 
256 different samples (Table 1), and even larger variability in gonadulin expression has previously

257 been reported for the crab Portunus trituberculatus (Veenstra, 2020). This shows that data from a

258 single SRA are not necessarily informative as to the level of gonadulin expression in this organ.

259 Interestingly, in some spider transcriptomes gonadulin expression is also observed in silk glands

260 (Table1, Suppl. Spreadsheet 2).

261

262 Arthropod insulin-like growth factors

263 Most insect ilps contain only a few amino acid residues after the sixth cysteine residue in the

264 precursor and sometimes there are none, however some ilps have a long C-terminal extension.

265 Such ilps are commonly present in hemimetabolous insects as well as several holometabolous

266 species (Fig. 4, Fig. S2 , Suppl. Spreadsheet 1). In some species the C-terminal extension of these

267 peptides are easily missed since if one ignores an intron donor site in the genome sequence the

268 conceptual translation of such sequences predicts much smaller ilps that look similar to the well

269 known Drosophila peptides. Nevertheless, analysis of RNAseq SRAs from several species shows

270 that such intron donor sites are functional. These C-terminal extensions are coded by two

271 additional exons that are not present in the typical insect neuroendocrine insulin genes. These

272 extensions are not only commonly present, but also look similar to one another, providing further

273 evidence that they are genuine parts of these ilps (Fig. 4). Furthermore, Trinity analysis of SRAs

274 containing reads for such transcripts reveals that they are alternatively spliced which leads to the

275 production of precursors with different C-terminal extensions. The difference often consists of

276 the inclusion or exclusion of a sequence rich in dibasic amino acid residues, mostly arginines,

277 that in many species has two characteristic cysteine residues. The alternative splice site is in the

278 middle in of what is usually the third coding exon, the last coding exon of these genes is less well

279 conserved but contains a sequence that conforms more or less to the $\mathrm{GTVX}_{1} \mathrm{PX}_{2}(\mathrm{~F} / \mathrm{Y})$ consensus

280 sequence. Such genes are present in species as diverse as cockroaches, termites, stick insects,

281 beetles, bees, ants and moths (Fig. 5). Interestingly, in the stick insect Timema cristinae this gene

282 underwent a local gene duplication, with one gene coding a peptide with the arginine-rich peptide

283 sequence and the second one lacking it.

284 In hemiptera ilp genes exist that similarly code for C-terminally extended ilps that are

285 alternatively spliced, but in those species the extended C-terminals of the predicted peptides are

286 not as well conserved (Fig. S3). Other C-terminally extended ilps were found in spiders and 
287 scorpions, but in those species no evidence was found for alternative splicing. Such C-terminally 288 extended ilps appear absent from decapods (Veenstra, 2020).

289 The term insulin-like growth factors was initially used as a description of substances in plasma 290 that had insulin-like biological activity, but it is now mostly used as a name for the vertebrate 291 hormones that are predominantly made in the liver. The use of the same term for both a group of 292 molecules that have similar characteristics as well two specific hormones is confusing. This is 293 particularly the case for insects, since hormones that have been called insulin-like growth factors 294 are not necessarily orthologs of one another nor of these vertebrate hormones. One of the two 295 types of insect insulin-like growth factors, Bombyx IGF-like peptide (BIGFLP; Okamoto et al., 296 2009a), has only been found in Bombyx mori, although it can be expected to be present in other 297 Lepidoptera as well. The insulin-like growth factor described above from several insect species 298 seems to be commonly present in arthropods, including Bombyx mori and I propose to call it 299 arthropod insulin-like growth factor (aIGF).

300 The data from an extended set of Bombyx transcriptome SRAs shows that in this species both 301 insulin-like growth factors are expressed by the fat body, but the temporal patterns of expression 302 of the two differ. Thus, aIGF is also expressed in larvae, when there is very little expression of 303 BIGFLP while during the pupal stage their peaks of expression do not coincide (Fig. 6).

304 Alternative splicing of aIGF mRNA in the silkworm and the honey bee is variable between the 305 different samples (Fig. 7, Fig S4). In Bombyx SRAs from adults show a relatively higher 306 expression of the longer isoform that has the additional sequence rich in dibasic amino acid 307 residues (Fig. S5), while in the honeybee those are more common in SRAs from the bodies of

308 larvae destined to become queens as well as in samples from the Nasonov glands from nurse bees 309 and in the only available sample of queen heads (Fig. S4). In most species there are insufficient 310 data or a single isoform may be predominantly expressed such as in the bumblebee (Suppl.

311 Spreadsheet 2).

\section{Is Drosophila ilp 6 an aIGF ortholog?}

314 Given the absence of prominent sequence similarity between Drosophila ilp 6 and the aIGFs

315 from more basal insect species, the obvious question is whether or not Drosophila ilp 6 is an 316 ortholog of aIGF or whether it arose independently. The archetype aIGF gene contains four 317 coding exons, the first two of which code for the insulin structure. The third consists of two parts, 
318 the first half which is present in both isoforms and the last part of this exon which is alternatively

319 sliced. The fourth and last coding exon contains the $\mathrm{GTVX}_{1} \mathrm{PX}_{2}(\mathrm{~F} / \mathrm{Y})$ consensus sequence.

320 During evolution, this basic pattern has been modified on several occasions. In Oncopeltus and

321 other hemiptera the third coding exon was modified, while in both the mosquito Aedes aegypti

322 and the honeybee, the intron between the first two coding exons was eliminated. In Aedes other

323 changes occurred as well, but the gene can still be recognized as an aIGF gene by the presence of

324 an exon that shows sequence similarity to the fourth coding exon of the aIGF genes. Soldier flies

325 and robber flies have aIGF genes that are complete except for the third coding exons. It thus

326 seems that the third coding exon was lost when Diptera evolved (Fig. 8). However, whereas the

327 aIGF genes in those flies can still be recognized as such by the presence of what once was the

328 fourth coding exon of a classical aIGF gene, this exon is not only absent from Drosophila, but is

329 missing from all Erenomeura (Fig. 8). There are two possible explanations for this absence, either

330 this exon was also lost, or the entire aIGF gene was lost and a novel insulin-like growth factor-

331 like gene evolved in those flies, perhaps not unlike the origin of BIGFLP in Bombyx. The amino

332 acid sequences of the aIGFs from the most highly developed non-Eremoneura flies are very

333 similar to those from the least evolved Erenomeura flies (Fig. S6). So the aIGF gene persisted but

334 it lost the last coding exon reminiscent of a classical aIGF gene and the only physico-chemical

335 characteristic that separates aIGF from the neuroendocrine insulins is the very short sequence

336 connecting the putative A- and B-chains.

\section{Arthropod relaxins}

339 The arthropod relaxins are known from a large number of arthropods, although they are lacking

340 in many insect species. As noted previously they have by far the best conserved amino acid

341 sequences in both the A- and B-chains of all the protostomian ilps and paralogs of this particular

342 peptide are also found in other protostomians and even some basal deuterostomes. Neuropeptides

343 containing cysteine residues typically have them in pairs, since as soon a cysteine containing

344 peptide enters the endoplasmatic reticulum these residues get oxidized and form disulfide

345 bridges. For this reason it is very surprising to see a decapod relaxin having seven cysteine

346 residues (Fig. 9). The presence of this particular cysteine is unlikely to be an artifact as it is found

347 in relaxins from a number of decapod species from different orders (Fig. S7). Although most

348 arthropods appear to have a single relaxin gene, two scorpion genomes have two such genes; in 
349 both cases the predicted amino acid sequence of one of the relaxins seems less conserved 350 (Veenstra, 2016a).

\section{Gonadulin, relaxin and aIGF likely evolved from a local gene triplication}

352 The very large primary amino acid sequence variability of arthropod ilps makes it difficult to 353 establish their phylogenetic affinities. Sequence similarity trees show that the gonadulins 354 resemble one another and hence may share a common ancestor, but such trees do not provide

355 details. Synteny offers another means to establish evolutionary relationships and, as chance has it, 356 the genomes of some species suggests that aIGF, gonadulin and arthropod relaxin originated from 357 an ancient gene triplication. Thus the three genes coding gonadulin, aIGF and relaxin are located 358 next to one another in the genomes of the German cockroach and the termite Zootermopsis 359 nevadensis. In the stick insect Timema cristinae the aIGF underwent a local duplication (see 360 above) and the four genes coding the two aIGFs, gonadulin and relaxin, are also next to one 361 another. Furthermore, in the genomes from the spiders Parasteatoda tepidariorum and Pardosa 362 363 pseudoannulata the gonadulin genes are next to an aIGF gene, which in these spiders has undergone one or more local duplications (Fig. 10). Such a close genomic association of these genes strongly suggests that they arose from a local gene triplication.

\section{Receptors}

366 Two different types of receptors are used by ilps, LGRs and RTKs. Insects have two different types of insulin RTKs, that have been labeled A and B. Most species have one gene coding an type A and one gene coding for an B type B RTK. However, cockroaches, termites and at least some stick insects have two B type RTKs and the American cockroach has also two type A RTKs. The genome assembly of the American cockroach shows that the two type A RTKs originated from a local gene duplication, as did the two type B RTKs. In Lepidoptera and Diptera all insulin RTKs are type A and there is no type B RTK. However, Lepidoptera do have a second gene coding for a protein with clear structural similarity to insulin RTKs, but these proteins lack the tyrosine kinase domain. I have called those proteins Insulin RTK-like (IRTKL). This gene is more similar to the type B RTKs than type A and it may have evolved from those RTKs. The presence of an IRTKL coding gene in at least two genomes from Trichoptera, suggests that it may have evolved before the two groups diverged. Interestingly, the genome of the beetle 
379 IRTKL orthologs was detected in any of other sequenced beetle genomes, but such an ortholog 380 was found in the transcriptome data of Tenebrio molitor, a species that is closely related to

381 Tribolium. A phylogenetic tree of the various RTKs and IRTKL proteins suggests that the origin 382 of the IRTKL proteins in Lepidoptera is ancient, but that of Tribolium is quite recent, indicating 383 convergent evolution (Fig. 11). In chelicerates there are also two types of RTK, while there are 384 four in decapods (Veenstra, 2020), however the various gene duplications of the arthropod RTKs 385 occurred after these groups diverged (Fig. 11).

386 Drosophila LGR3 is activated by Drosophila ilp 8 and orthologs of this receptor are present in 387 many but not all arthropods, always in a single copy. As described LGR4 is likely the arthropod 388 relaxin receptor and is similarly present in many arthropods, usually in a single copy, but 389 chelicerates have two copies and some spider have even three. LGR3 and LGR4 are closely 390 related GPCRs together with another receptor that was first described from the pond snail 391 Lymnaea stagnalis as GRL101 (Tensen et al., 1994) to stress its similarity with LGR3 and LGR4 392 it is called here LGR5. The strong sequence similarity of LGR5 with LGR3 and LGR4 suggests 393 that it, like LGR3 and LGR4 might have an insulin-like ligand and for this reason it is included 394 here. LGR5 is commonly present in arthropods. Unlike LGR3 and LGR4, that are missing in 395 many insect species, LGR5 is consistently present in hemimetabolous insects, but it is completely 396 absent from all holometabolous insects (the GRL101 from Rhagoletis zephyria [XP_017487580] is appears to be a mite GPCR). In both chelicerates and decapods there are usually several paralogs (Fig. 12). All three of these receptors are widely expressed and it is difficult to discern clear expression patterns (Suppl. Spreadsheet 2).

400

\section{Discussion}

402 I describe a number of novel arthropod ilps, the gonadulins and aIGFs, that are putative orthologs 403 of Drosophila ilp 8 and ilp 6 respectively and I present evidence that the genes coding these 404 peptides and relaxin are commonly present in arthropods and most likely originated from an 405 ancient gene triplication.

406 There are four arguments that together suggests that the various gonadulins and Drosophila ilp 8 407 are indeed orthologs. First, the gonadulins cluster together with Drosophila ilp 8 on on a 408 sequence similarity tree that bundles peptides with similar structures. It is clear that even though 409 the amino acid sequences of the gonadulins are poorly conserved, they do resemble one another 410 better than each one of them resembles any of the better known arthropod ilps. Secondly, for 
411 those members of this group where this could be determined, they are all made by the gonads,

412 although this is not the only tissue expressing these peptides and expression by the gonads is

413 variable. Thirdly, all species for which a gonadulin could be identified also have an ortholog of

414 Drosophila LGR3, even though not all arthropod species have such a receptor. Unfortunately,

415 due to the large structural variability of the gonadulins, it was not always possible to demonstrate

416 the existence of a gonadulin gene in each species that has an ortholog of LGR3. Nevertheless, no

417 gonadulins were found in species lacking such a receptor. Finally, peptides that were identified as

418 putative gonadulins, but that are present in species as distantly related as spiders on one hand and

419 stick insects and cockroaches on the other, are produced by genes for which orthology is

420 independently confirmed by synteny with aIGF genes.

421 The physiological significance of the presence of both aIGF and BIGFLP in Bombyx is an

422 intriguing question, perhaps even more so as there seems to be only a single insulin receptor in

423 this species that might induce an intracellular response. As shown by the data of an impressive set

424 of transcriptome SRAs from this species, expression of the two differs during development (Fig.

425 6). Although the physiological meaning of this remains to be investigated, it is tempting to

426 speculate that it is related to oogenesis and metamorphosis taking place simultaneously. In most

427 insect species juvenile hormone and ecdysone play preponderant roles in the regulation of both

428 processes, but using the same hormones for two different processes at the same time might be

429 counterproductive and may have led to the evolution of BIGFLP.

430 It has been reported previously that, unlike Drosophila, most insect species have more than one

431 insulin RTK (Kremer, Korb \& Bornberg-Bauer, 2016). This is confirmed here and in the

432 American cockroach there are actually four insulin RTKs. The presence of three insulin RTKs in

433 termites has led to the suggestion that they might be involved in caste determination (Kremer,

434 Korb \& Bornberg-Bauer, 2016). Although this may be so, it is somewhat surprising in this

435 context that the American cockroach, a close relative, has even four such receptors, yet has no

436 caste system. In Lepidoptera and at least two tenebrionid beetles one of the putative insulin

437 receptors lacks the tyrosine kinase domain, like the vertebrate IGF2 receptor and the Drosophila

438 decoy insulin receptor (Okamoto et al., 2013). The Drosophila receptor also lacks the

439 transmembrane domaine and is released into the hemolymph. These receptors may well have

440 similars role in regulating the hemolymph ilp concentrations.

441 In some insects the expression of insulin RTKs have been studied sometimes together with the

442 effects of inactivating one or both insulin RTKs by RNAi (Wheeler, Buck \& Evans, 2006; Sang

443 et al., 2016; Okada et al., 2019). Interestingly, in honeybee larvae that are changed from worker 
444 food to royal jelly, that is rich in proteins, it is the RTK A that is upregulated (Wheeler, Buck \& 445 Evans, 2006), whereas in two beetle species the effects of RTK inactivation by RNAi is much 446 stronger for type A than for type B (Sang et al., 2016; Okada et al., 2019). In the honeybee and 447 the beetle Gnatocerus these receptors have been indirectly linked to an aIGF peptide. In Diptera 448 and in the head louse there is only a single RTK, which in both case are also type A and this is 449 also the type that is most abundantly expressed in insects. This suggests that the A type insulin 450 RTK is more important than the B type RTK.

451 The structural difference between neuroendocrine ilps and aIGFs, as illustrated by the large C452 terminal extensions absent in the former but present in the latter, suggest the use of different 453 receptors. Indeed, the similarities between insulin and vertebrate IGF on one hand and insect 454 neuroendocrine ilps and aIGF on the other, are striking. Thus whereas the liver is the major tissue 455 expressing IGF, in insects aIGF is expressed by the fat body, the tissue that performs the 456 functions of both the vertebrate liver and adipose tissue. Furthermore, both IGF and aIGF are Cterminally extended insulin-like molecules and in both cases the primary transcripts produced are 458 alternatively spliced (Roberts et al., 1987). Finally, insulin and IGF act on two RTKs and many 459 insects also seem to have two insulin RTKs, although structural similarity is insufficient proof 460 that these are insulin receptors, as illustrated by the insulin receptor-related receptor that functions as an alkali receptor (Deyev et al., 2011). Nevertheless, this suggests that the Cterminal extension of aIGF may allow for the differential activation of two different types of insulin RTKs and the presence of only one insulin receptor in Diptera may well explain why Drosophila ilp 6 has lost this C-terminal extension. Furthermore, it is perhaps no coincidence that the ilps that did not separately clearly into either an aIGF or an insulin branch on the sequence similarity tree (Fig. 2) are from Drosophila, Glossina and Pediculus. These are species that have only one insulin RTK and thus there would be no physiological need to maintain different molecular structures for peptides in order to preferentially activate one or the other of the two insulin RTKs.

The close genomic association of the gonadulin, relaxin and IGF genes in some arthropod genomes suggest that they originated from an ancient gene triplication. Although the primary amino acid sequences of the different gonadulins is limited, as discussed above, there is reason to believe they are also orthologs and the same holds for the various aIGFs. The Drosophila gonadulin (dilp 8) receptor has been shown to be Drosophila LGR3, while LGR4 must be an

475 arthropod relaxin receptor. As demonstrated by the sequence similarity of their transmembrane 476 regions, these LGRs and LGR5 are evolutionary cousins. Insect aIGFs on the other hand are 
477 known to stimulate RTKs. When neuropeptide genes undergo a local duplication the ligands they

478 encode either keep using the same receptor or use paralogs that have their origin in a gene

479 duplication of the receptor. The gene coding aIGF that uses an RTK is flanked on both sides by

480 genes that code LGR ligands. The only reasonable explanation is that the original gene coding for

481 an insulin-like peptide (the one that got triplicated) used both types of receptors, i.e. it had two

482 receptors, both an LGR and an RTK.

483 It is clear that during evolution at least holometabolous species no longer have such a GPCR, as

484 these species have at most only two such receptors, LGR3 and LGR4 (for gonadulin and relaxin

485 respectively), while some species have none. Nevertheless, it is interesting to note that the

486 hemimetabolous insects have LGR5, a receptor that is evolutionarily closely related to the

487 receptors for gonadulin and relaxin. Thus LGR5 could be a second receptor for aIGF. If this were

488 so, then the remarkable absence of LGR5 from holometabolous species might be related to the

489 switch to holometaboly itself. Maggots and caterpillars undergo essentially linear growth, while

490 in non-holometabolous species, growth is accompanied by development at the same time.

491 Perhaps, LGR5 stimulated by aIGF is responsible for this.

492 Arthropod relaxin has an primary amino acid sequence that is much better conserved than that of 493 the typical arthropod insulins or IGFs. As arthropod relaxin shares what seem to be the structural 494 characteristics common to both aIGF and neuroendocrine insulins, it seems plausible that relaxin 495 can also stimulate the insulin RTK. It is of interest in this respect that Drosophila relaxin, ilp7, 496 binds to the decoy insulin receptor as well other Drosophila ilps (Okamoto et al., 2013) and 497 previous work suggested that it acts through the Drosophila RTK (Linneweber et al., 2014).

498 When there is only a single receptor for a ligand, both can co-evolve and over time structures of 499 both the ligand and its receptor may change. However, when the ligand activates two different 500 receptors, all three components have to coevolve and one would expect that this would restrain

501 the structures of all three elements much more than when there is only a single receptor and such 502 restraints would be the strongest on the ligand that activates both receptors. This might explain

503 why arthropod relaxin is so well conserved.

504 It is tempting to speculate that orthologous genes have similar expression patterns and functions.

505 In related species this is a reasonable hypothesis and the observed expression of aIGFs in 506 cockroaches (Castro-Arnau et al., 2019) and beetles (Okada et al., 2019) is predominantly in the

507 fat body and this seems to be the case for Bombyx aIGF too. What is likely the Rhodnius aIGF is 508 also expressed by the fat body (Defferrari, Orchard \& Lange, 2015) as is Drosophila ilp 6

509 (Okamoto et al., 2009b). This suggest that within insects these peptides have the same function. It 
510 is notable however, that at least in Pardosa spiders the fat body does not express aIGF but a

511 specific insulin (Yu et al., 2020), while aIGFs expression is limited to the cephalothorax. This

512 suggests that in spiders aIGFs are expressed in the brain, is indeed observed in the spider

513 Stegodyphus dumicola (Suppl. Spreadsheet 2). In decapods, which are more closely related to

514 insects than chelicerates, no aIGFs were found (Veenstra, 2020). The phylogenetic tree of the

515 various arthropod insulin RTKs also shows that the various paralogs of this receptor are not direct

516 orthologs of one another, but must have evolved independently in each subphylum or even class.

517 This within arthropods the functions of the various insulin-like peptides may be significantly

518 different. It suggests that the apparent resemblance between insect neuroendocrine insulins and

519 aIGF on one hand and insulin and IGF on the other could reflect a case of convergent evolution

520 rather than one of orthology.

521 In the beetle Gnatocerus cornutus it has been shown that aIGF specifically stimulates the growth

522 of a sexual ornament (Okada et al., 2019), while higher levels of aIGF are observed in honeybee

523 larvae that are destined to become queens and thus develop functional ovaries (Wheeler, Buck \&

524 Evans, 2006). In Gnatocerus aIGF release depends on nutrition status and in honeybees protein

525 rich royal jelly is associated with in increase of aIGF. Although we don't know as much detail for

526 Blattella aIGF, its expression is strongly inhibited during starvation (Castro-Arnau et al., 2019).

527 This suggests that in insects aIGF is released by the fat body in response to nutritious food.

528 The physiological function of gonadulin is less clear. Insulin and related peptides typically

529 stimulate growth and reproduction, so its presence in the ovaries and testes suggests a function in

530 reproduction. Its presence in unfecundated eggs of Blattella suggests that within the ovary it are

531 the oocytes themselves that express gonadulin, likely the follicle cells that in Drosophila have

532 been shown to express Drosophila ilp 8 (Liao \& Nässel, 2020). In the crab Portunus

533 trituberculatus gonadulin expression is on occasion very high in the gonads (Veenstra, 2020), but

534 the very variable degree of expression makes it difficult to see this hormone as merely

535 stimulating reproduction. The expression of gonadulin in hematopoetic tissue and the anterior

536 proliferation center of the brain in Procambarus clarkii (Veenstra, 2020), neither suggest a role

537 limited to reproduction but hints at a more general role in promoting growth. Spider silks are

538 proteins and thus its production requires plenty of amino acids, not unlike vitellogenesis, or the

539 development and reparation of imaginal disks. Gonadulin secreted by these organs might

540 therefore suggest that, not unlike insulin, it stimulates growth, but more intensely and/or more

541 localized. Such an intensified stimulation of growth might be achieved by increasing not only the

542 uptake of glucose as an energy substrate but also that of amino acids. Under this hypothesis, it 
543 might act as both an autocrine to stimulate uptake of metabolites and an endocrine to make these

544 available and by doing so it might be able to stimulate growth of specific organs, such as

545 imaginal disks and/or gonads that secrete it.

546

547

548

549

Conclusions

550 A local gene triplication in an early ancestor likely yielded three genes coding gonadulin,

551 arthropod insulin-like growth factor and relaxin. Orthologs of these genes are now commonly

552 present in arthropods and almost certainly include the Drosophila insulin-like peptides 6, 7 and 8.

553

554

555

556

557

558

559

560

561

562

563

564

565

566

567

568

569

570

571

572

573

574

575

576

577

578

579

580

581

\section{Acknowledgements}

I thank an anonymous reviewer and Jennifer Hackney Price for reviewing my manuscript, I also acknowledge the contributions made by all those who not only produced but also made available the numerous SRAs that I analyzed here. This work would neither have been possible without the various programs employed.

\section{References}

Almagro Armenteros JJ, Tsirigos KD, Sønderby CK, Petersen TN, Winther O, Brunak S, von Heijne G, Nielsen H. 2019. SignalP 5.0 improves signal peptide predictions using deep neural networks. Nat Biotechnol. 37:420-423. doi: 10.1038/s41587-019-0036-z.

Attardo GM, Abd-Alla AMM, Acosta-Serrano A, Allen JE, Bateta R, Benoit JB, Bourtzis K, Caers J, Caljon G, Christensen MB, Farrow DW, Friedrich M, Hua-Van A, Jennings EC, Larkin DM, Lawson D, Lehane MJ, Lenis VP, Lowy-Gallego E, Macharia RW, Malacrida AR, Marco HG, Masiga D, Maslen GL, Matetovici I, Meisel RP, Meki I, Michalkova V, Miller WJ, Minx P, Mireji PO, Ometto L, Parker AG, Rio R, Rose C, Rosendale AJ, Rota-Stabelli O, Savini G, Schoofs L, Scolari F, Swain MT, Takáč P, Tomlinson C, Tsiamis G, Van Den Abbeele J, Vigneron A, Wang J, Warren WC, Waterhouse RM, Weirauch MT, Weiss BL, Wilson RK, Zhao X, Aksoy S. 2019. Comparative genomic analysis of six Glossina genomes, vectors of African trypanosomes. Genome Biol. 20:187. doi: 10.1186/s13059-019-1768-2. 
582 Brogiolo W, Stocker H, Ikeya T, Rintelen F, Fernandez R, Hafen E. 2001. An evolutionarily

583 conserved function of the Drosophila insulin receptor and insulin-like peptides in growth control.

584 Curr Biol. 11:213-221. doi: 10.1016/s0960-9822(01)00068-9.

585 Cao Z, Yu Y, Wu Y, Hao P, Di Z, He Y, Chen Z, Yang W, Shen Z, He X, Sheng J, Xu X, Pan B, 586 Feng J, Yang X, Hong W, Zhao W, Li Z, Huang K, Li T, Kong Y, Liu H, Jiang D, Zhang B, Hu

587 J, Hu Y, Wang B, Dai J, Yuan B, Feng Y, Huang W, Xing X, Zhao G, Li X, Li Y, Li W. 2013.

588 The genome of Mesobuthus martensii reveals a unique adaptation model of arthropods. Nat 589 Commun. 4:2602. doi: 10.1038/ncomms3602.

590 Castellanos MC, Tang JC, Allan DW. 2013. Female-biased dimorphism underlies a female591 specific role for post-embryonic Ilp7 neurons in Drosophila fertility. Development. 140:3915-

592 3926. doi: 10.1242/dev.094714.

593 Castro-Arnau J, Marín A, Castells M, Ferrer I, Maestro JL. 2019. The expression of cockroach

594 insulin-like peptides is differentially regulated by physiological conditions and affected by

595 compensatory regulation. J Insect Physiol. 114:57-67. doi: 10.1016/j.jinsphys.2019.02.010.

596 Chandler JC, Gandhi NS, Mancera RL, Smith G, Elizur A, Ventura T. 2017. Understanding

597 Insulin Endocrinology in Decapod Crustacea: Molecular Modelling Characterization of an

598 Insulin-Binding Protein and Insulin-Like Peptides in the Eastern Spiny Lobster, Sagmariasus

599 verreauxi. Int J Mol Sci. 18. pii: E1832. doi: 10.3390/ijms18091832.

600 Colombani J, Andersen DS, Léopold P. 2012. Secreted peptide Dilp8 coordinates Drosophila

601 tissue growth with developmental timing. Science. 336:582-5. doi: 10.1126/science.1216689.

602 Colombani J, Andersen DS, Boulan L, Boone E, Romero N, Virolle V, Texada M, Léopold P.

603 2015. Drosophila Lgr3 Couples Organ Growth with Maturation and Ensures Developmental

604 Stability. Curr Biol. 25:2723-2729. doi: 10.1016/j.cub.2015.09.020.

605 Defferrari MS, Orchard I, Lange AB. 2015. An insulin-like growth factor in Rhodnius prolixus is 606 involved in post-feeding nutrient balance and growth. Front Neurosci. 10:566. doi:

607 10.3389/fnins.2016.00566.

608 Deyev IE, Sohet F, Vassilenko KP, Serova OV, Popova NV, Zozulya SA, Burova EB, Houillier

609 P, Rzhevsky DI, Berchatova AA, Murashev AN, Chugunov AO, Efremov RG, Nikol'sky NN,

610 Bertelli E, Eladari D, Petrenko AG. 2011. Insulin receptor-related receptor as an extracellular

611 alkali sensor. Cell Metab. 13:679-689. doi: 10.1016/j.cmet.2011.03.022.

612 Garelli A, Gontijo AM, Miguela V, Caparros E, Dominguez M. 2012. Imaginal discs secrete

613 insulin-like peptide 8 to mediate plasticity of growth and maturation. Science. 336:579-582. doi:

614 10.1126/science.1216735.

615 Garelli A, Heredia F, Casimiro AP, Macedo A, Nunes C, Garcez M, Dias ARM, Volonte YA,

616 Uhlmann T, Caparros E, Koyama T, Gontijo AM. 2015. Dilp8 requires the neuronal relaxin

617 receptor Lgr3 to couple growth to developmental timing. Nat Commun. 6:8732. doi:

618 10.1038/ncomms9732.

619 Gontijo AM, Garelli A. 2018. The biology and evolution of the Dilp8-Lgr3 pathway: A relaxin-

620 like pathway coupling tissue growth and developmental timing control. Mech Dev. 154:44-50.

621 doi: 10.1016/j.mod.2018.04.005. 
622 Gouy M, Guindon S, Gascuel O. 2010. SeaView version 4: A multiplatform graphical user

623 interface for sequence alignment and phylogenetic tree building. Mol Biol Evol. 2010

624 Feb;27(2):221-4. doi: 10.1093/molbev/msp259.

625 Grabherr MG, Haas BJ, Yassour M, Levin JZ, Thompson DA, Amit I, Adiconis X, Fan L,

626 Raychowdhury R, Zeng Q, Chen Z, Mauceli E, Hacohen N, Gnirke A, Rhind N, di Palma F,

627 Birren BW, Nusbaum C, Lindblad-Toh K, Friedman N, Regev A. 2011. Full-length

628 transcriptome assembly from RNA-Seq data without a reference genome. Nat Biotechnol.

629 15;29:644-652. doi: 10.1038/nbt.1883.

630 Grbić M, Van Leeuwen T, Clark RM, Rombauts S, Rouzé P, Grbić V, Osborne EJ, Dermauw W, 631 Ngoc PC, Ortego F, Hernández-Crespo P, Diaz I, Martinez M, Navajas M, Sucena É, Magalhães

632 S, Nagy L, Pace RM, Djuranović S, Smagghe G, Iga M, Christiaens O, Veenstra JA, Ewer J, 633 Villalobos RM, Hutter JL, Hudson SD, Velez M, Yi SV, Zeng J, Pires-daSilva A, Roch F, 634 Cazaux M, Navarro M, Zhurov V, Acevedo G, Bjelica A, Fawcett JA, Bonnet E, Martens C, 635 Baele G, Wissler L, Sanchez-Rodriguez A, Tirry L, Blais C, Demeestere K, Henz SR, Gregory 636 TR, Mathieu J, Verdon L, Farinelli L, Schmutz J, Lindquist E, Feyereisen R, Van de Peer Y.

637 2011. The genome of Tetranychus urticae reveals herbivorous pest adaptations. Nature. 479:487638 492. doi: 10.1038/nature10640.

639 Grönke S, Clarke DF, Broughton S, Andrews TD, Partridge L. 2010. Molecular evolution and 640 functional characterization of Drosophila insulin-like peptides. PLoS Genet. 6:e1000857. doi:

641 10.1371/journal.pgen.1000857.

642 Harrison MC, Jongepier E, Robertson HM, Arning N, Bitard-Feildel T, Chao H, Childers CP, 643 Dinh H, Doddapaneni H, Dugan S, Gowin J, Greiner C, Han Y, Hu H, Hughes DST, Huylmans 644 AK, Kemena C, Kremer LPM, Lee SL, Lopez-Ezquerra A, Mallet L, Monroy-Kuhn JM, Moser 645 A, Murali SC, Muzny DM, Otani S, Piulachs MD, Poelchau M, Qu J, Schaub F, Wada646 Katsumata A, Worley KC, Xie Q, Ylla G, Poulsen M, Gibbs RA, Schal C, Richards S, Belles X,

647 Korb J, Bornberg-Bauer E. 2018. Hemimetabolous genomes reveal molecular basis of termite 648 eusociality. Nat Ecol Evol. 2:557-566. doi: 10.1038/s41559-017-0459-1.

649 Herndon N, Shelton J, Gerischer L, Ioannidis P, Ninova M, Dönitz J, Waterhouse RM, Liang C, 650 Damm C, Siemanowski J, Kitzmann P, Ulrich J, Dippel S, Oberhofer G, Hu Y, Schwirz J, 651 Schacht M, Lehmann S, Montino A, Posnien N, Gurska D, Horn T, Seibert J, Vargas Jentzsch 652 IM, Panfilio KA, Li J, Wimmer EA, Stappert D, Roth S, Schröder R, Park Y, Schoppmeier M, 653 Chung HR, Klingler M, Kittelmann S, Friedrich M, Chen R, Altincicek B, Vilcinskas A,

654 Zdobnov E, Griffiths-Jones S, Ronshaugen M, Stanke M, Brown SJ, Bucher G. 2020. Enhanced 655 genome assembly and a new official gene set for Tribolium castaneum. BMC Genomics. 21:47.

656 doi: 10.1186/s12864-019-6394-6.

657 Jaszczak JS, Wolpe JB, Bhandari R, Jaszczak RG, Halme A. 2016. Growth coordination during

658 Drosophila melanogaster imaginal disc regeneration is mediated by signaling through the relaxin 659 receptor LGR3 in the prothoracic gland. 204:703-709. doi: 10.1534/genetics.116.193706.

660 Kawamoto M, Jouraku A, Toyoda A, Yokoi K, Minakuchi Y, Katsuma S, Fujiyama A, Kiuchi T, 661 Yamamoto K, Shimada T. 2019. High-quality genome assembly of the silkworm, Bombyx mori. 662 Insect Biochem Mol Biol. 107:53-62. doi: 10.1016/j.ibmb.2019.02.002. 
663 Kremer LPM, Korb J, Bornberg-Bauer E. 2016. Reconstructed evolution of insulin receptors in 664 insects reveals duplications in early insects and cockroaches. J Exp Zool B Mol Dev Evol.

665 330:305-311. doi: 10.1002/jez.b.22809.

666 Lange A, Beier S, Huson DH, Parusel R, Iglauer F, Frick JS. 2018. Genome Sequence of

667 Galleria mellonella (Greater Wax Moth). Genome Announc. 6. pii: e01220-17. doi:

668 10.1128/genomeA.01220-17.

669 Li S, Zhu S, Jia Q, Yuan D, Ren C, Li K, Liu S, Cui Y, Zhao H, Cao Y, Fang G, Li D, Zhao X, 670 Zhang J, Yue Q, Fan Y, Yu X, Feng Q, Zhan S. 2018. The genomic and functional landscapes of

671 developmental plasticity in the American cockroach. Nat Commun. 9:1008. doi: 10.1038/s41467672 018-03281-1.

673 Liao S, Nässel DR. 2020. Drosophila insulin-like peptide 8 (DILP8) in ovarian follicle cells 674 regulates ovulation and metabolism. bioRxiv. doi: https://doi.org/10.1101/2020.05.02.073585.

675 Linneweber GA, Jacobson J, Busch KE, Hudry B, Christov CP, Dormann D, Yuan M, Otani T, 676 Knust E, de Bono M, Miguel-Aliaga I. 2014. Neuronal control of metabolism through nutrient677 dependent modulation of tracheal branching. Cell. 156:69-83. doi: 10.1016/j.cell.2013.12.008.

678 Liu Y, Liao S, Veenstra JA, Nässel DR. 2016. Drosophila insulin-like peptide 1 (DILP1) is 679 transiently expressed during non-feeding stages and reproductive dormancy. Sci Rep. 6:26620. 680 doi: 10.1038/srep26620.

681 Liu S, Aageaard A, Bechsgaard J, Bilde T. 2019. DNA Methylation Patterns in the Social Spider, 682 Stegodyphus dumicola. 2019. Genes (Basel). 10. pii: E137. doi: 10.3390/genes10020137. 683 Matthews BJ, Dudchenko O, Kingan SB, Koren S, Antoshechkin I, Crawford JE, Glassford WJ, 684 Herre M, Redmond SN, Rose NH, Weedall GD, Wu Y, Batra SS, Brito-Sierra CA, Buckingham 685 SD, Campbell CL, Chan S, Cox E, Evans BR, Fansiri T, Filipović I, Fontaine A, Gloria-Soria A, 686 Hall R, Joardar VS, Jones AK, Kay RGG, Kodali VK, Lee J, Lycett GJ, Mitchell SN, Muehling 687 J, Murphy MR, Omer AD, Partridge FA, Peluso P, Aiden AP, Ramasamy V, Rašić G, Roy S, 688 Saavedra-Rodriguez K, Sharan S, Sharma A, Smith ML, Turner J, Weakley AM, Zhao Z, Akbari 689 OS, Black WC 4th, Cao H, Darby AC, Hill CA, Johnston JS, Murphy TD, Raikhel AS, Sattelle 690 DB, Sharakhov IV, White BJ, Zhao L, Aiden EL, Mann RS, Lambrechts L, Powell JR, 691 Sharakhova MV, Tu Z, Robertson HM, McBride CS, Hastie AR, Korlach J, Neafsey DE, 692 Phillippy AM, Vosshall LB. 2018. Improved reference genome of Aedes aegypti informs 693 arbovirus vector control. Nature. 563:501-507. doi: 10.1038/s41586-018-0692-z.

694 Miguel-Aliaga I, Thor S, Gould AP. 2008. Postmitotic specification of Drosophila insulinergic

695 neurons from pioneer neurons. PLoS Biol 6: e58. doi:10.1371/journal.pbio.0060058.

696 Mizoguchi A, Okamoto N. 2013. Insulin-like and IGF-like peptides in the silkmoth Bombyx

697 mori: discovery, structure, secretion, and function. Front Physiol. 2013 4:217. doi:

698 10.3389/fphys.2013.00217.

699 Murphy CT, Hu PJ. 2013. Insulin/insulin-like growth factor signaling in C. elegans. WormBook, 700 ed. The C. elegans Research Community, WormBook. 2013. doi: 10.1895/wormbook.1.164.1. 701 Nagasawa H, Kataoka H, Isogai A, Tamura S, Suzuki A, Ishizaki H, Mizoguchi A, Fujiwara Y, 702 Suzuki A. 1984. Amino-terminal amino Acid sequence of the silkworm prothoracicotropic 703 hormone: homology with insulin. Science.226:1344-1345. doi: 10.1126/science.226.4680.1344. 
704 Nagasawa H, Kataoka H, Isogai A, Tamura S, Suzuki A, Mizoguchi A, Fujiwara Y, Suzuki A,

705 Takahashi SY, Ishizaki H. 1986. Amino acid sequence of a prothoracicotropic hormone of the

706 silkworm Bombyx mori. Proc Natl Acad Sci U S A. 83:5840-5843. doi: 10.1073/pnas.83.16.5840.

707 Nässel DR, Vanden Broeck J. 2016. Insulin/IGF signaling in Drosophila and other insects:

708 factors that regulate production, release and post-release action of the insulin-like peptides. Cell

709 Mol Life Sci. 2016 Jan;73(2):271-90. doi: 10.1007/s00018-015-2063-3.

710 O’Brien LE, Soliman SS, Li X, Bilder D. 2011. Altered modes of stemcell division drive

711 adaptive intestinal growth. Cell 147:603-614. doi: 10.1016/j.cell.2011.08.048.

712 Okada Y, Katsuki M, Okamoto N, Fujioka H, Okada K. 2019a. A specific type of insulin-like

713 peptide regulates the conditional growth of a beetle weapon. PLoS Biol. 17:e3000541. doi:

714 10.1371/journal.pbio.3000541.

715 Okamoto N, Yamanaka N, Satake H, Saegusa H, Kataoka H, Mizoguchi A. 2009a. An

716 ecdysteroid-inducible insulin-like growth factor-like peptide regulates adult development of the

717 silkmoth Bombyx mori. FEBS J. 276:1221-1332. doi: 10.1111/j.1742-4658.2008.06859.x.

718 Okamoto N, Yamanaka N, Yagi Y, Nishida Y, Kataoka H, O'Connor MB, Mizoguchi A. $2009 \mathrm{~b}$.

719 A fat body-derived IGF-like peptide regulates postfeeding growth in Drosophila. Dev Cell.

720 17:885-891. doi: 10.1016/j.devcel.2009.10.008.

721 Okamoto N, Nakamori R, Murai T, Yamauchi Y, Masuda A, Nishimura T. 2013. A secreted

722 decoy of InR antagonizes insulin/IGF signaling to restrict body growth in Drosophila. Genes

723 Dev. 27:87-97. doi: 10.1101/gad.204479.112.

724 Panfilio KA, Vargas Jentzsch IM, Benoit JB, Erezyilmaz D, Suzuki Y, Colella S, Robertson HM,

725 Poelchau MF, Waterhouse RM, Ioannidis P, Weirauch MT, Hughes DST, Murali SC, Werren JH,

726 Jacobs CGC, Duncan EJ, Armisén D, Vreede BMI, Baa-Puyoulet P, Berger CS, Chang CC, Chao

727 H, Chen MM, Chen YT, Childers CP, Chipman AD, Cridge AG, Crumière AJJ, Dearden PK,

728 Didion EM, Dinh H, Doddapaneni HV, Dolan A, Dugan S, Extavour CG, Febvay G, Friedrich

729 M, Ginzburg N, Han Y, Heger P, Holmes CJ, Horn T, Hsiao YM, Jennings EC, Johnston JS,

730 Jones TE, Jones JW, Khila A, Koelzer S, Kovacova V, Leask M, Lee SL, Lee CY, Lovegrove

731 MR, Lu HL, Lu Y, Moore PJ, Munoz-Torres MC, Muzny DM, Palli SR, Parisot N, Pick L, Porter

732 ML, Qu J, Refki PN, Richter R, Rivera-Pomar R, Rosendale AJ, Roth S, Sachs L, Santos ME,

733 Seibert J, Sghaier E, Shukla JN, Stancliffe RJ, Tidswell O, Traverso L, van der Zee M, Viala S,

734 Worley KC, Zdobnov EM, Gibbs RA, Richards S. 2019. Molecular evolutionary trends and

735 feeding ecology diversification in the Hemiptera, anchored by the milkweed bug genome.

736 Genome Biol. 20:64. doi: 10.1186/s13059-019-1660-0.

737 Price MN, Dehal PS, Arkin AP. 2010. FastTree 2--approximately maximum-likelihood trees for

738 large alignments. PLoS One. 5:e9490. doi: 10.1371/journal.pone.0009490.

739 Riesch R, Muschick M, Lindtke D, Villoutreix R, Comeault AA, Farkas TE, Lucek K, Hellen E,

740 Soria-Carrasco V, Dennis SR, de Carvalho CF, Safran RJ, Sandoval CP, Feder J, Gries R, Crespi

741 BJ, Gries G, Gompert Z, Nosil P. 2017. Transitions between phases of genomic differentiation

742 during stick-insect speciation. Nat Ecol Evol. 1:82. doi: 10.1038/s41559-017-0082.

743 Roberts CT Jr, Lasky SR, Lowe WL Jr, Seaman WT, LeRoith D. 1987. Molecular cloning of rat

744 insulin-like growth factor I complementary deoxyribonucleic acids: differential messenger 
745 ribonucleic acid processing and regulation by growth hormone in extrahepatic tissues. Mol

746 Endocrinol. 1:243-248. doi: 10.1210/mend-2-6-528.

747 Rutherford K, Parkhill J, Crook J, Horsnell T, Rice P, Rajandream MA, Barrell B. 2000. Artemis:

748 sequence visualization and annotation. Bioinformatics. 16:944-945. doi: 10.1093/bioinformatics/

749 16.10.944.

750 Sang M, Li C, Wu W, Li B. 2016. Identification and evolution of two insulin receptor genes

751 involved in Tribolium castaneum development and reproduction. Gene. 585:196-204. doi:

752 10.1016/j.gene.2016.02.034.

753 Schwager EE, Sharma PP, Clarke T, Leite DJ, Wierschin T, Pechmann M, Akiyama-Oda Y,

754 Esposito L, Bechsgaard J, Bilde T, Buffry AD, Chao H, Dinh H, Doddapaneni H, Dugan S,

755 Eibner C, Extavour CG, Funch P, Garb J, Gonzalez LB, Gonzalez VL, Griffiths-Jones S, Han Y,

756 Hayashi C, Hilbrant M, Hughes DST, Janssen R, Lee SL, Maeso I, Murali SC, Muzny DM,

757 Nunes da Fonseca R, Paese CLB, Qu J, Ronshaugen M, Schomburg C, Schönauer A, Stollewerk

758 A, Torres-Oliva M, Turetzek N, Vanthournout B, Werren JH, Wolff C, Worley KC, Bucher G,

759 Gibbs RA, Coddington J, Oda H, Stanke M, Ayoub NA, Prpic NM, Flot JF, Posnien N, Richards

760 S, McGregor AP. 2017. The house spider genome reveals an ancient whole-genome duplication

761 during arachnid evolution. BMC Biol. 15:62. doi: 10.1186/s12915-017-0399-x.

762 Sievers F, Wilm A, Dineen D, Gibson TJ, Karplus K, Li W, Lopez R, McWilliam H, Remmert

763 M, Söding J, Thompson JD, Higgins DG. 2011. Fast, scalable generation of high-quality protein

764 multiple sequence alignments using Clustal Omega. Mol Syst Biol. 7:539. doi:

765 10.1038/msb.2011.75.

766 Slaidina M, Delanoue R, Gronke S, Partridge L, Léopold P. 2009. A Drosophila insulin-like

767 peptide promotes growth during nonfeeding states. Dev Cell. 17:874-884. doi:

768 10.1016/j.devcel.2009.10.009.

769 Seecof RL, Dewhurst S. 1974. Insulin is a Drosophila hormone and acts to enhance the

770 differentiation of embryonic Drosophila cells. Cell Differ 3: 63-70. doi: 10.1016/0045-

771 6039(74)90041-4.

772 Smit AB, Vreugdenhil E, Ebberink RH, Geraerts WP, Klootwijk J, Joosse J.1988. Growth-

773 controlling molluscan neurons produce the precursor of an insulin-related peptide. Nature.

774 31:535-538. doi: 10.1038/331535a0.

775 Tensen CP, Van Kesteren ER, Planta RJ, Cox KJ, Burke JF, van Heerikhuizen H, Vreugdenhil E.

776 1994. A G protein-coupled receptor with low density lipoprotein-binding motifs suggests a role

777 for lipoproteins in G-linked signal transduction. Proc Natl Acad Sci U S A. 91:4816-4820. doi:

778 10.1073/pnas.91.11.4816.

779 Terrapon N, Li C, Robertson HM, Ji L, Meng X, Booth W, Chen Z, Childers CP, Glastad KM,

780 Gokhale K, Gowin J, Gronenberg W, Hermansen RA, Hu H, Hunt BG, Huylmans AK, Khalil

781 SM, Mitchell RD, Munoz-Torres MC, Mustard JA, Pan H, Reese JT, Scharf ME, Sun F, Vogel

782 H, Xiao J, Yang W, Yang Z, Yang Z, Zhou J, Zhu J, Brent CS, Elsik CG, Goodisman MA,

783 Liberles DA, Roe RM, Vargo EL, Vilcinskas A, Wang J, Bornberg-Bauer E, Korb J, Zhang G,

784 Liebig J. 2014. Molecular traces of alternative social organization in a termite genome. Nat

785 Commun. 5:3636. doi: 10.1038/ncomms4636. 
786 Vallejo DM, Juarez-Carreño S, Bolivar J, Morante J, Dominguez M. 2015. A brain circuit that

787 synchronizes growth and maturation revealed through Dilp8 binding to Lgr3. Science.

788 50:aac6767. doi: 10.1126/science.aac6767.

789 Veenstra JA. 2014. The contribution of the genomes of a termite and a locust to our

790 understanding of insect neuropeptides and neurohormones. Front Physiol. 5:454. doi:

791 10.3389/fphys.2014.00454.

792 Veenstra JA. 2016a. Neuropeptide evolution: Chelicerate neurohormone and neuropeptide genes

793 may reflect one or more whole genome duplications. Gen Comp Endocrinol. 229:41-55. doi:

794 10.1016/j.ygcen.2015.11.019.

795 Veenstra JA. 2016b. Similarities between decapod and insect neuropeptidomes. PeerJ :e2043.

796 doi: 10.7717/peerj.2043.

797 Veenstra JA. 2020. Gonadulins, the fourth type of Insulin-related peptides in Decapods. Gen

798 Comp Endocrinol., in press. doi: 10.1016/j.ygcen.2020.113528.

799 Veenstra JA, Rombauts S, Grbić M. 2012. In silico cloning of genes encoding neuropeptides, 800 neurohormones and their putative G-protein coupled receptors in a spider mite. Insect Biochem

801 Mol Biol. 42:277-295. doi: 10.1016/j.ibmb.2011.12.009.

802 Wheeler DE, Buck N, Evans JD. 2006. Expression of insulin pathway genes during the period of

803 caste determination in the honey bee, Apis mellifera. Insect Mol Biol. 15:597-602. doi:

804 10.1111/j.1365-2583.2006.00681.x.

805 Yang CH, Belawat P, Hafen E, Jan LY, Jan YN. 2008. Drosophila egg-laying site selection as a

806 system to study simple decision-making processes. Science 319: 1679-1683. doi:

807 10.1126/science.1151842.

808 Yu N, Li J, Liu M, Huang L, Bao H, Yang Z, Zhang Y, Gao H, Wang Z, Yang Y, Van Leeuwen

809 T, Millar NS, Liu Z. 2019. Genome sequencing and neurotoxin diversity of a wandering spider

810 Pardosa pseudoannulata (pond wolf spider). BioRxiv. doi: https://doi.org/10.1101/747147.

811 Yu N, Han C, Liu Z. 2020. In silico identification of the neuropeptidome of the pond wolf spider

812 Pardosa pseudoannulata. Gen Comp Endocrinol. 285:113271. doi:

813 10.1016/j.ygcen.2019.113271.

814 Zhan S, Fang G, Cai M, Kou Z, Xu J, Cao Y, Bai L, Zhang Y, Jiang Y, Luo X, Xu J, Xu X,

815 Zheng L, Yu Z, Yang H, Zhang Z, Wang S, Tomberlin JK, Zhang J, Huang Y. 2020. Genomic

816 landscape and genetic manipulation of the black soldier fly Hermetia illucens, a natural waste

817 recycler. Cell Res. 2020 30:50-60. doi: 10.1038/s41422-019-0252-6. 


\section{Figure 1}

Gonadulin sequence alignment.

Note the very large sequence variability of the gonadulin propeptides. Cysteine residues are highlighted in red, other conserved amino residues in black and conserved substitutions in grey. Sequences are from Suppl. Spreadsheet 1. 
Drosophila

Apis

Athalia

Pediculus

Acyrthosiphon

Cimex

Gryllus

Timema

Blattela

Daphnia

Paralithodes-1

Paralithodes -2

Latrodectus

Pardosa-1

Tetranychus

Drosophila

Apis

Athalia

Pediculus

Acyrthosiphon

Cimex

Gryllus

Timema

Blattela

Daphnia

Paralithodes-1

Paralithodes-2

Latrodectus

Pardosa-1

Tetranychus

Drosophila

Apis

Athalia

Pediculus

Acyrthosiphon

Cimex

Gryllus

Timema

Blattela

Daphnia

Paralithodes -1

Paralithodes-2

Latrodectus

Pardosa-1

Tetranychus

Drosophila

Apis

Athalia

Pediculus

Acyrthosiphon

Cimex

Gryllus

Timema

Blattela

Daphnia

Paralithodes-1

Paralithodes-2

Latrodectus

Pardosa-1

Tetranychus

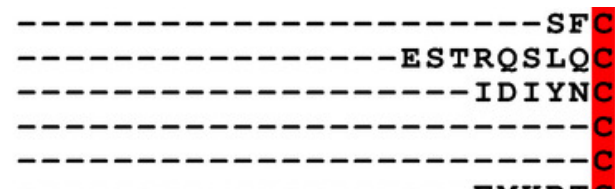

SLERMKKF AMEAC KN-IARDVIINS KM-KVRDMALKF D T KWIRLVYMMS GDEF I KNM I VNV SKDYLRFMVATA DHDQFRNFMRLS DKAR IMNY IMYS NR-KIRRQ I LES D P RAF RQA IVS I SARDVKLIATYV TPREIRRIANDV TGHDLLNVIKRA SGQDLVHVIARA TIKELQSARSRIC

-------------QQQRLDEMANV -ENLIRV
EHLFQADEGARRDRRS IEFAH-KGPRMKRSPEKSDTSN-TDQIVK SDPAGTRKKRDIS-------IG GKKKRDSSTSSFNE--------GMGGIKRSFPD---NSRPDS--SYAKREVSNDDVMKVVEEEFDKH QYHRRRREVRGAA--------SKKKRSPADH---------IIY SSEKGKRSAE-----------TFQRRD I HP I SASP DR-- - - NL HRRSVRSVALDENSEGDTYIM N I ARRS I - - - - - - - - - A I HKRNE-- - - - - - - - - - SIFKRSP--------------S L Y KRSY-- - - - - - - - - -

-HNKHHYISRS---ATISDV-IEENPVSIEIIEPEGSYHVQARMP LQHGFYGGYGLMPSRFGGIGQNYQS-TNFH $---A E S------E S E V Q-------R S-R D L E I G D P R F-----------------------$

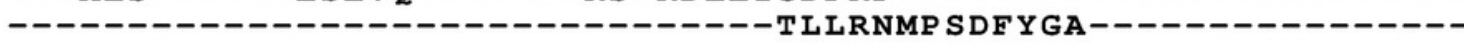
$------S L G L H F R------------------------------------G M V T----D V E$ FDDVGNYVTADNEIFHAP LNYRNHKHWREVPFKLFKNKRTTDKFGNFQSDWQNFMKISDNP PS----- - - - - - - - - - - - - - - - -

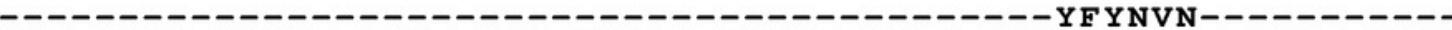

PGVGGSSVILPWRSLPPCDGPDGDCGGLNSADSPVQQTQRASPPQAPFNMAKRWYALHRFG

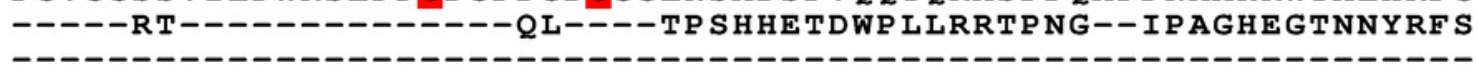
-- - - - - - - - - - - - - - - - - - - - - - - - - - - - - - - - - - - - - - - - - - -

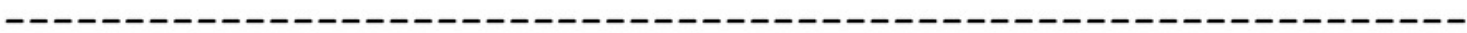

$--------S Y P M G G Y L K V------T R E H F N R L S E L D I F P R Y-----------K P$ IKP HHEK QSELITPGLEYMDTQYNGLSGGMYGSSLPMRPKYLLRSVKSDDLLGFNL--SPEELEELHD

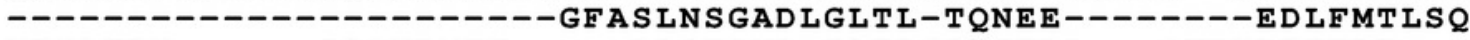
VKYLKEN-- - - DPQNPMFK-----DDQF LYR-ILEDGI HGF PD---QWEVDEINDD--REFKHLVGDIEEVDLLLK-TSNNKNKLKEPNVTP LWLR--PINLPGFRDD---RSRHPRIR

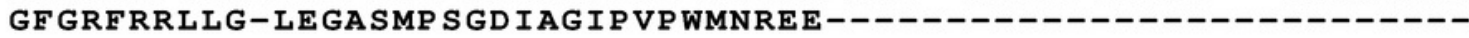

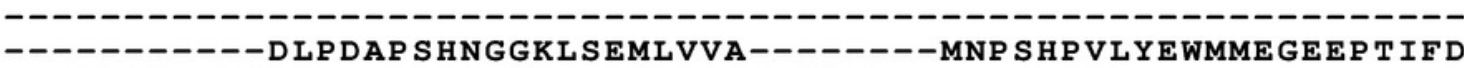
- YDTP SLPMHDE--P LQNAP S SALLGR I LGVP SQWT-- - - - ADDV-- - - - - - - - -

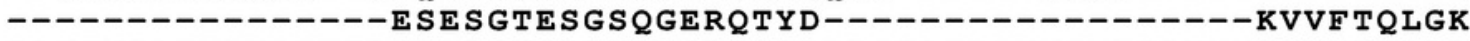
TAKGMQAEKENDITEDYRADSNSIDYAPSLSGALPLSELFPENVSKF IRVNYPKYVTSLLP LP SPLTLSSDVRP GVHSIIRSNTKLSQVLVP P LSNTI KARLASQAMVWR- LMLAGMVRRK - - - - - - - - - - - - - - - - - - - - - - - - - - - - - - - - - - - - - - - - -

K------HRFKRDHSSRSY -NNIPYC EIGD-RMPRNSKNLNKKIFQQIAMK R-- LSRAAKNKNQTMRMINAFAAK $---K I N----E N H R R S S K I D K I I E E C C$ G------DSGKATIIKRELMNDFRE $----L H S K G I N G N L L Y R D I R D T V M K$ - - AADDGGARVARSP SPEADIFAM $---D L S K K T R S I F V Y P E K A Q R V I E Q$ -- AVNNANRQVKRSPETIRQLMID ETLFFPVEVYTAKVKRHREFALHRK HKGKRD KEMS LPVVVPRS L SAIRQD - -RLNRRQTQHQSTTMTLEELRET - - - HDP T-QP THPLS I PLQDVSKV $----S E P E-D I L Y P R S I P L K D I A L V$ $----N P N S L M N W I R E R R A I S S I A S S C$

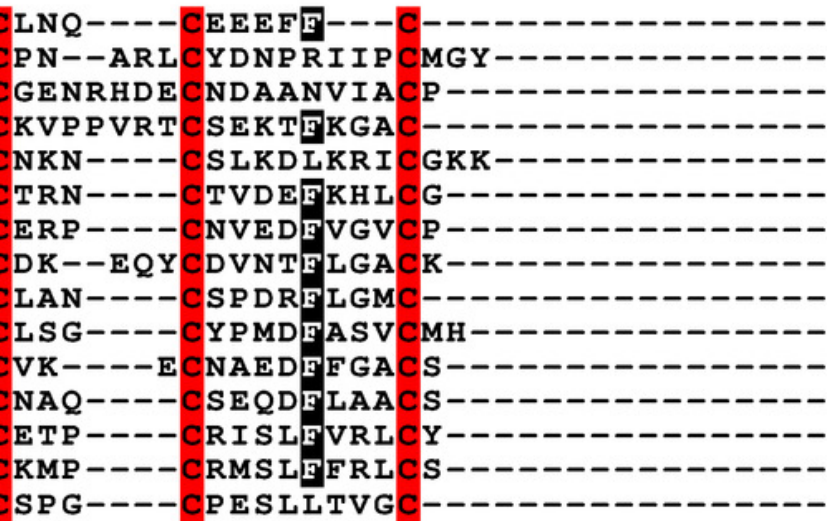


Figure 2

Insect ilp sequence similarity tree.

Note that the gonadulins and relaxins are well differentiated from the insulins and alGFs, but that the latter are only partially separated from one another on the tree. Sequences are from Suppl. Spreadsheet 1. 


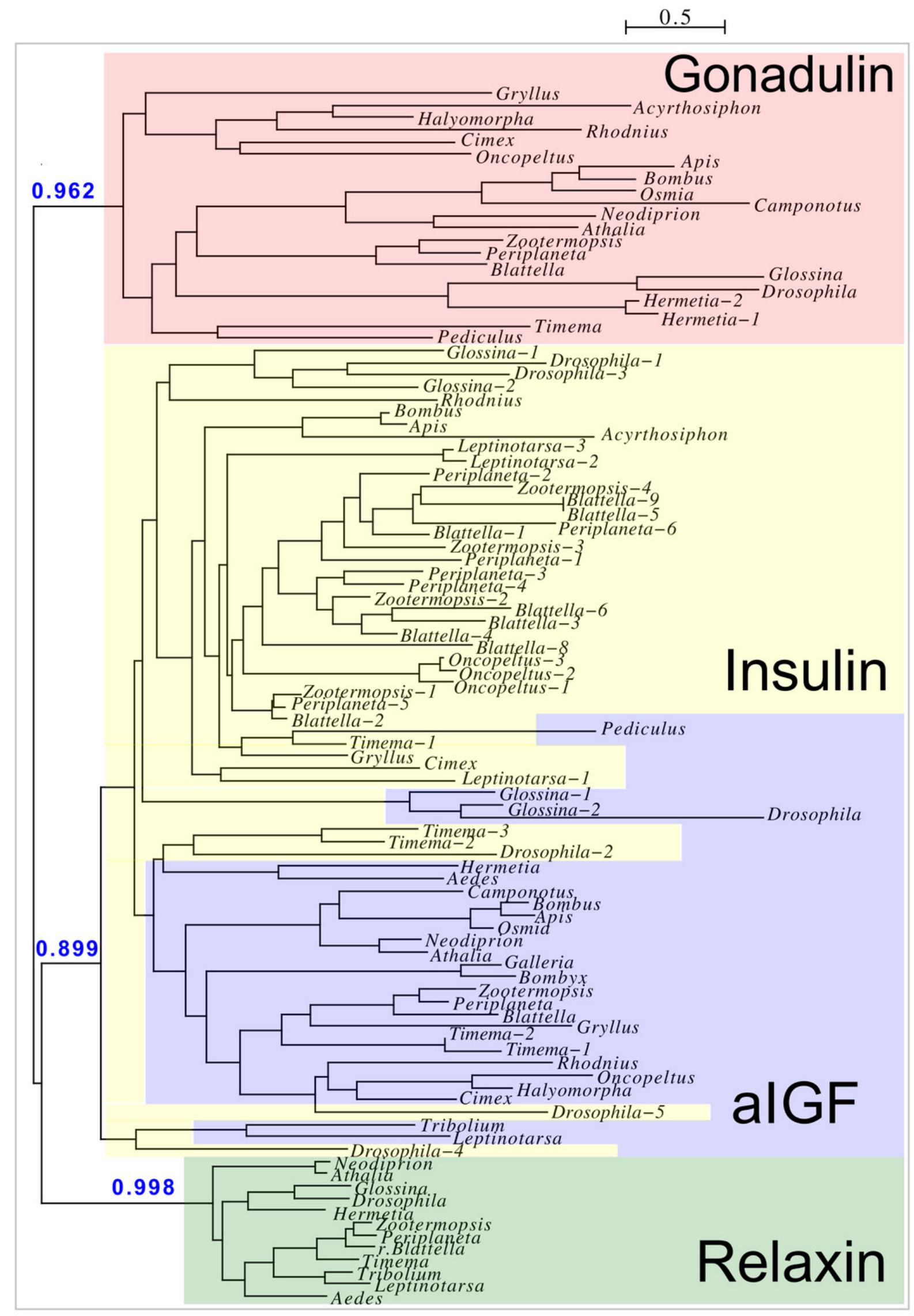


Figure 3

Radial arthropod ilp sequence similarity tree.

Note that the gonadulins cluster and are well separated from the other arthropod ilps. A more detailed sequence similarity tree with species names is present in the supplementary data as Fig. S1; sequences are from Suppl. Spreadsheet 1.

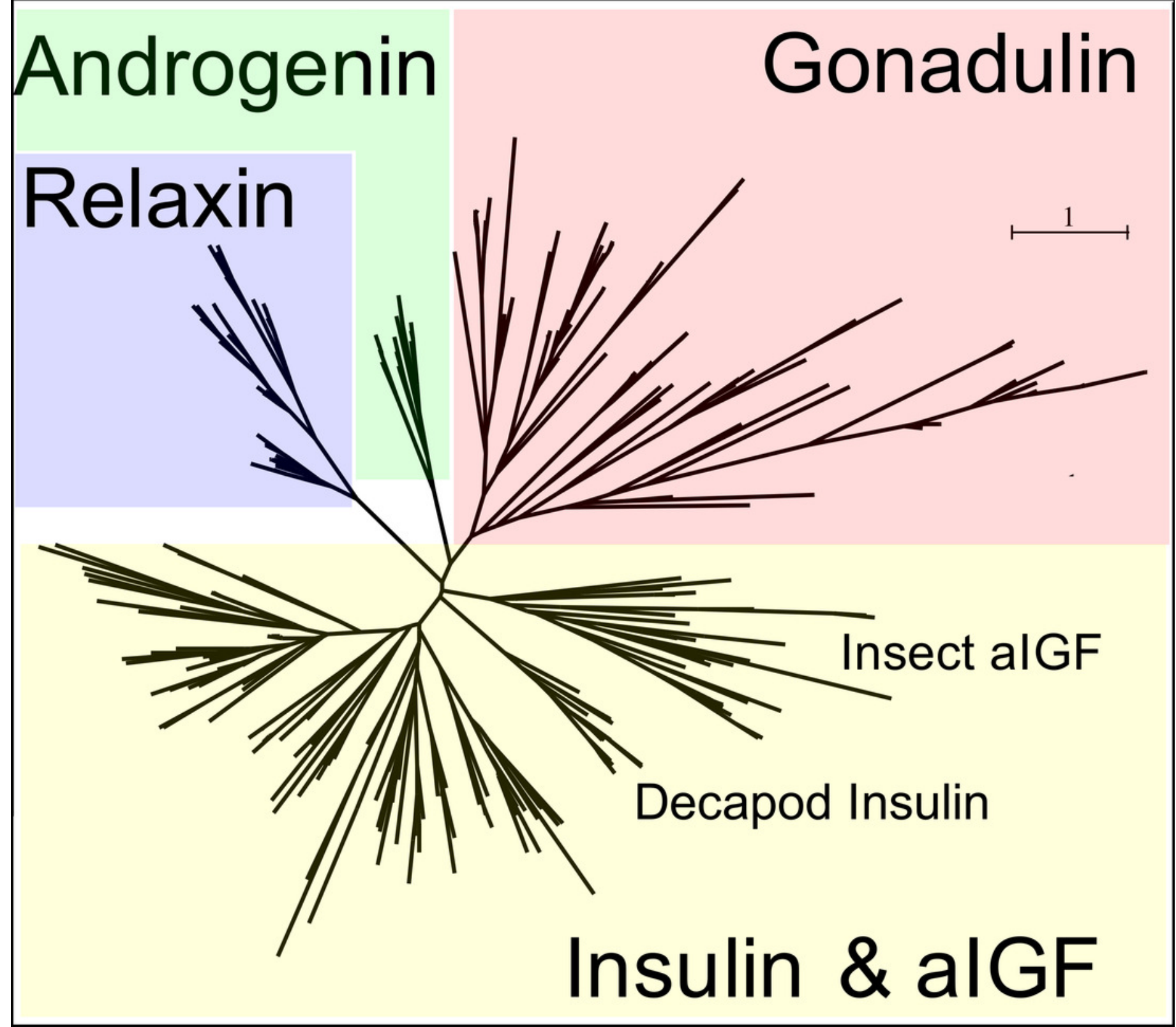




\section{Figure 4}

aIGF sequence alignment.

Sequence alignment of some insect aIGF propeptides; where applicable only the isoforms with the arginine-rich sequences are shown. Note that these proteins have three different regions with sequence similarity: the insulin subsequence, the arginine-rich sequence containing an additional disulfide bridge and the C-terminal parts (underlined in blue), that is also somewhat conserved in Gryllus rubens, even though that species lacks an arginine-rich subsequence. Sequences are from Suppl. Spreadsheet 1. Cysteine residues are indicated in red and the predicted disulfide bridges by lines. Other conserved amino acid residues are highlighted in black and conserved substitutions in grey. 
Drosophila Tribolium Bomby $x$ Bombus Gryllus Cimex Timema Blattella

Drosophila Tribolium Bomby $x$ Bombus Gryllus Cimex Timema Blattella

Drosophila Tribolium Bomby $x$ Bombus Gryllus Cimex Timema Blattella

Drosophila Tribolium Bomby $x$ Bombus Gryllus Cimex

Timema Blattella

Drosophila Tribolium Bomby $x$ Bombus Gryllus Cimex

Timema Blattella
-SPLAPTEYEQRRMMCSTGLSDVIQKICVSGTVALGDVFPNSF--------- - - - - - - GKRRKR

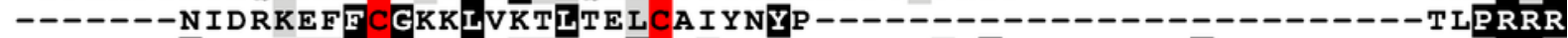

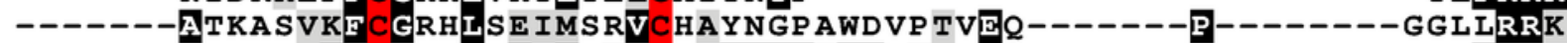

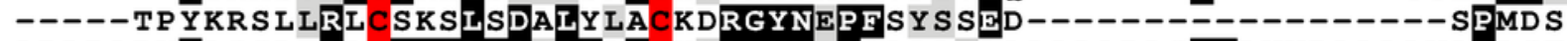
AP LPAPVAASGLTRA CGSLADLLAAVCHGRGYNDPQAAAAAAAAAAP ASPSAWVPAAAAVAPAGT

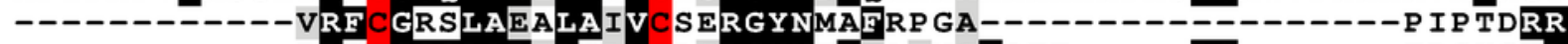
----------RRS CGSQLADILS LV CA GRG YNTPYAF NGEQTE-----PS------ TP S KSHR -------APPTIRMQMCGSQLANTLAQICSAYGYHDP FSQTRRVNS-----PSSG---VNTTPNRLR

\section{DLQNVTDLCCKSGGCTYRELLQY-CKG}

FRRQIVDECC-RSQCSRRYIVQYY CMEAHSSIAHLLKAKP EPEKPP--------ERPV-פAPKETP RQLGIADECC-LMGCTWEQLSEY-CSIIAYSESP LED-----LESHVIADRSAEQENLAAGAKTT T VGPGLAEECC-YHTCTYTQLQQY-CKPEKSSSVDAVNSPVWIEKYPYLSTRSATSSSLEVR---- ARA GVADLCC-RRGCSIRTLQQY-CSPADPRRSS---GPGAAAAAS - - - AAP AASGSAPAAAAAA YRRGIVDECC-HNGCSFSTLESY-CSEGSSDDSK---SPPYLQI SK----RSDSHKNMNKENK- -D VSRG ITHECC-KVGCSWKTMEEY-CIPGEAENKI---FD----------V---ESLINQIQ---VRRGVADECC-KTGCTLDTMEQY-CSAPLTPAQR---ARF - LQQYQ--- SNALNRILQ⿹VPP-- - -

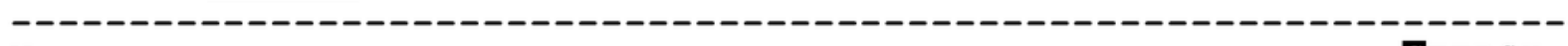

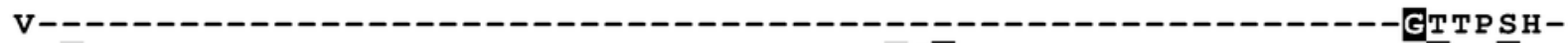
TTTTP-----------------AV----------VGSDE-------- HVHV----RGETGLA $------------S R S D I D Y V H G T I K---------C K I H G S K G A R R K G A N M D R D D D A G G C D R-K$ AGNDPAHSP PVRAMSEKRP YVDDQEMSDQYSDMMVKQST TYQHNVLQTRSS IENIDIKSDGTHHHKRKL-FGH I DDDQGGRAGH I

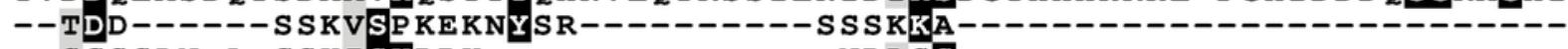
$--S G S S L N-A-G S K I S K D P K-------------N D L S S--------------------$

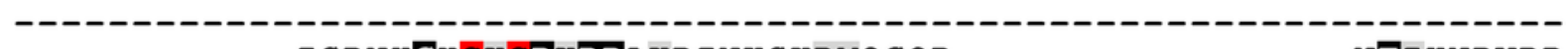

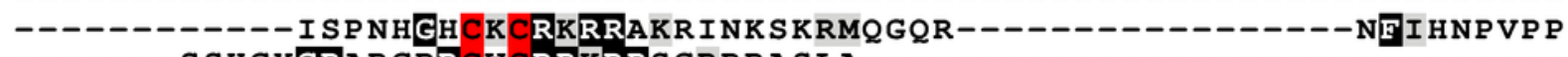
$------S S H G Y$ GRARGRRCWCRRKRRS GRRRAS LA--

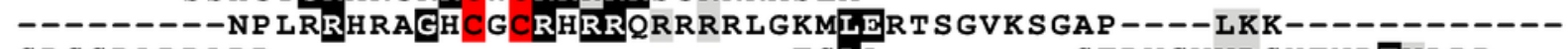
SP SSPAP P AP P - - - YPYSLDHHLYRKATGGNKVKRNEMRRS SMDS SHQRLESKLGHNPNENSLDWLRKSENDEISSNRHP ---KGHRKKKKKGRKGNGRCRCRRKQRKF D P- - EK I EQ

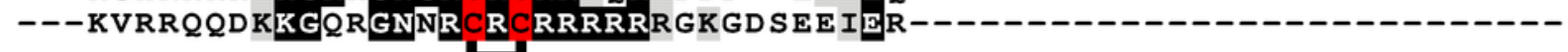

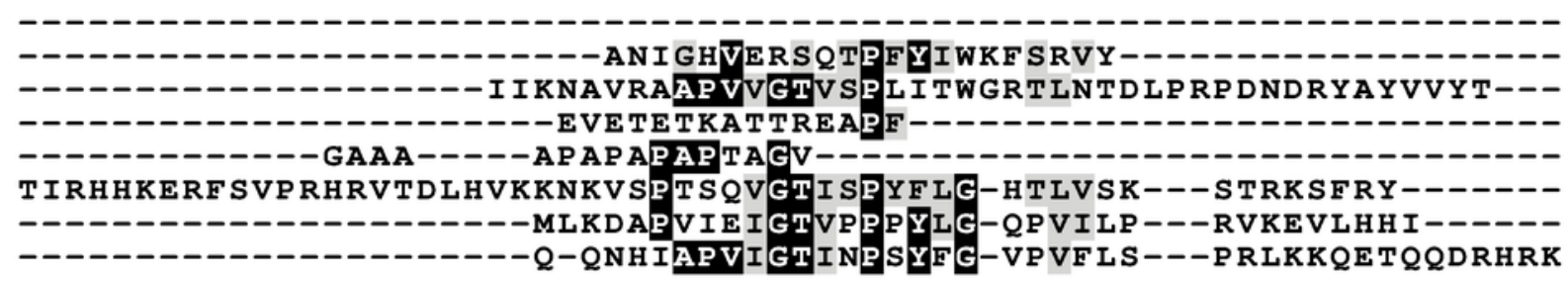




\section{Figure 5}

Intron-exon structures of aIGF genes.

(A) Bombyx mori, (B) Tribolium castaneum, (C) Apis mellifera, (D) Blattella germanica. In the top part for each species the gene structure with the exon represented as small colored boxes and the introns as a black line. The orange brown color in the first exon corresponds to the coding sequence of the signal peptide and the blue corresponds to the insulin sequence, while the red color corresponds to the coding sequence of the arginine-rich region that is alternatively spliced in the two isoforms produced from these genes. The yellow exons contains coding sequence for the $\mathrm{GTVX}_{1} \mathrm{PX}_{2}(\mathrm{~F} / \mathrm{Y})$ consensus sequence. The amino acid sequence coded by this alternatively spliced DNA sequence is indicated. The numbers 1 and 2 show the coding sequences of the two mRNA species produced from these gene using the same colors as for the gene structures. Note that the structures of these genes are very similar, with the major differences being the size of the introns, some of which are very large, as indicated by interruption sign in the gene structures, and the loss of an intron in Apis. The only other notable difference is that in the honey bee the second transcript is produced in a different fashion and only consists of one coding exon. The alternative splice site in this species have been indicated together with how this results in either splicing or the inclusion of a stop codon in the mRNA. 


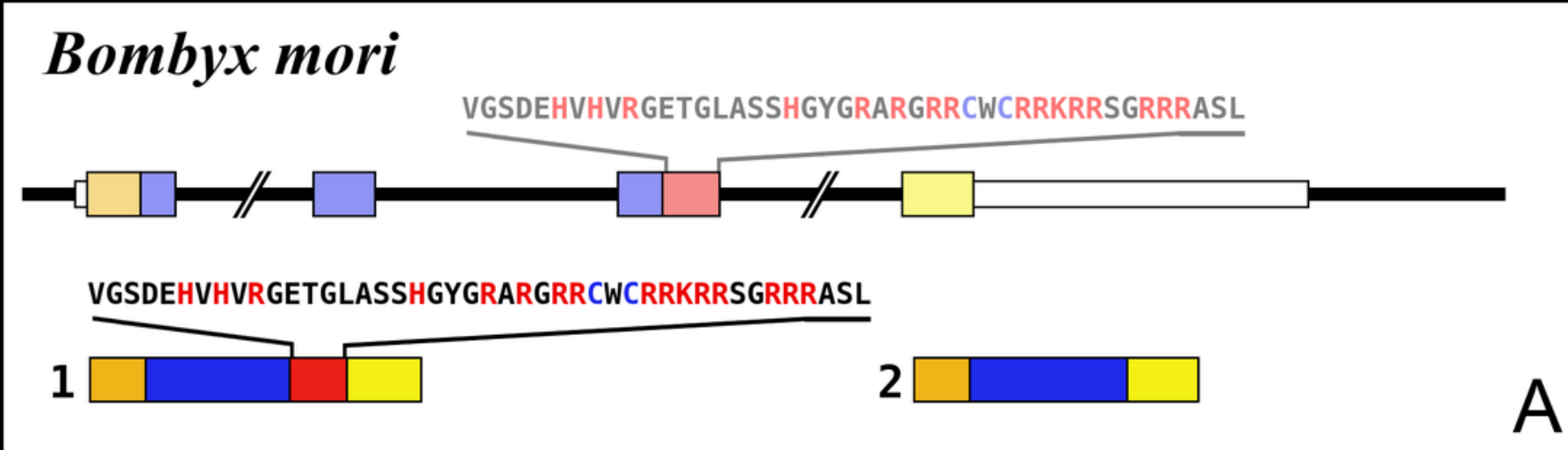

\section{Tribolium castaneum}

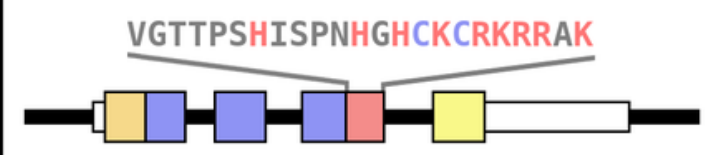

VGTTPSHISPNHGHCKCRKRRAK

1

2

\section{Apis mellifera}

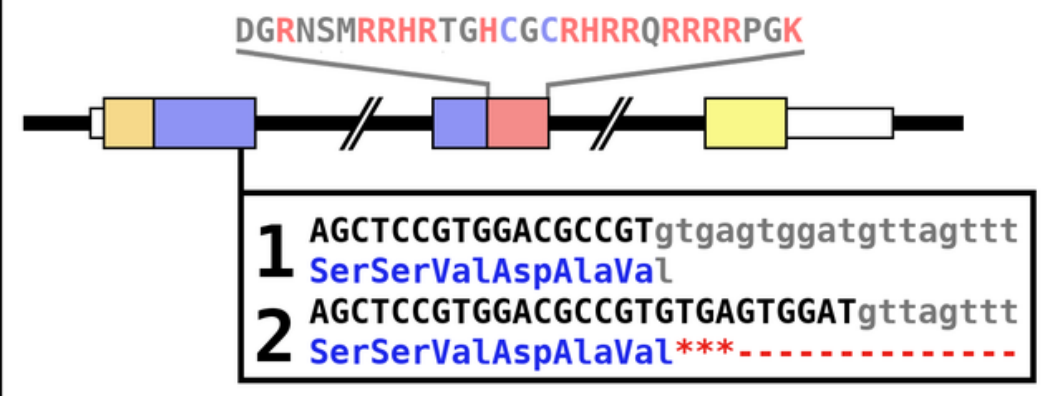

\section{DGRNSMRRHRTGHCGCRHRRQRRRRPGK}

1

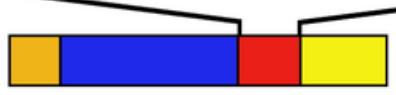

2

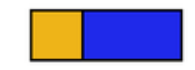

\section{Blattella germanica}

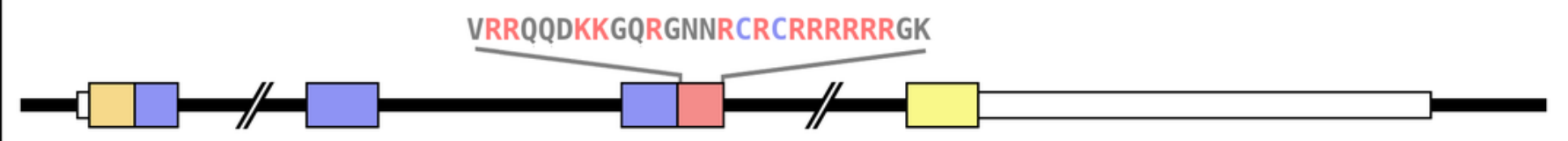

VRRQQDKKGQRGNNRCRCRRRRRRGK

1

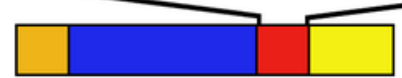

2 
Figure 6

Expression of aIGF and BIGFLP during development in Bombyx mori.

Number of reads per million present in SRAs of a single series of experiments where there are three experiments for each developmental stage. The three values corresponds to the maximum, minimun and average of those three. Scale to the left is for alGF, scale to the right for BIGFLP; note that the number of BIGFLP reads is much larger than those for alGF.

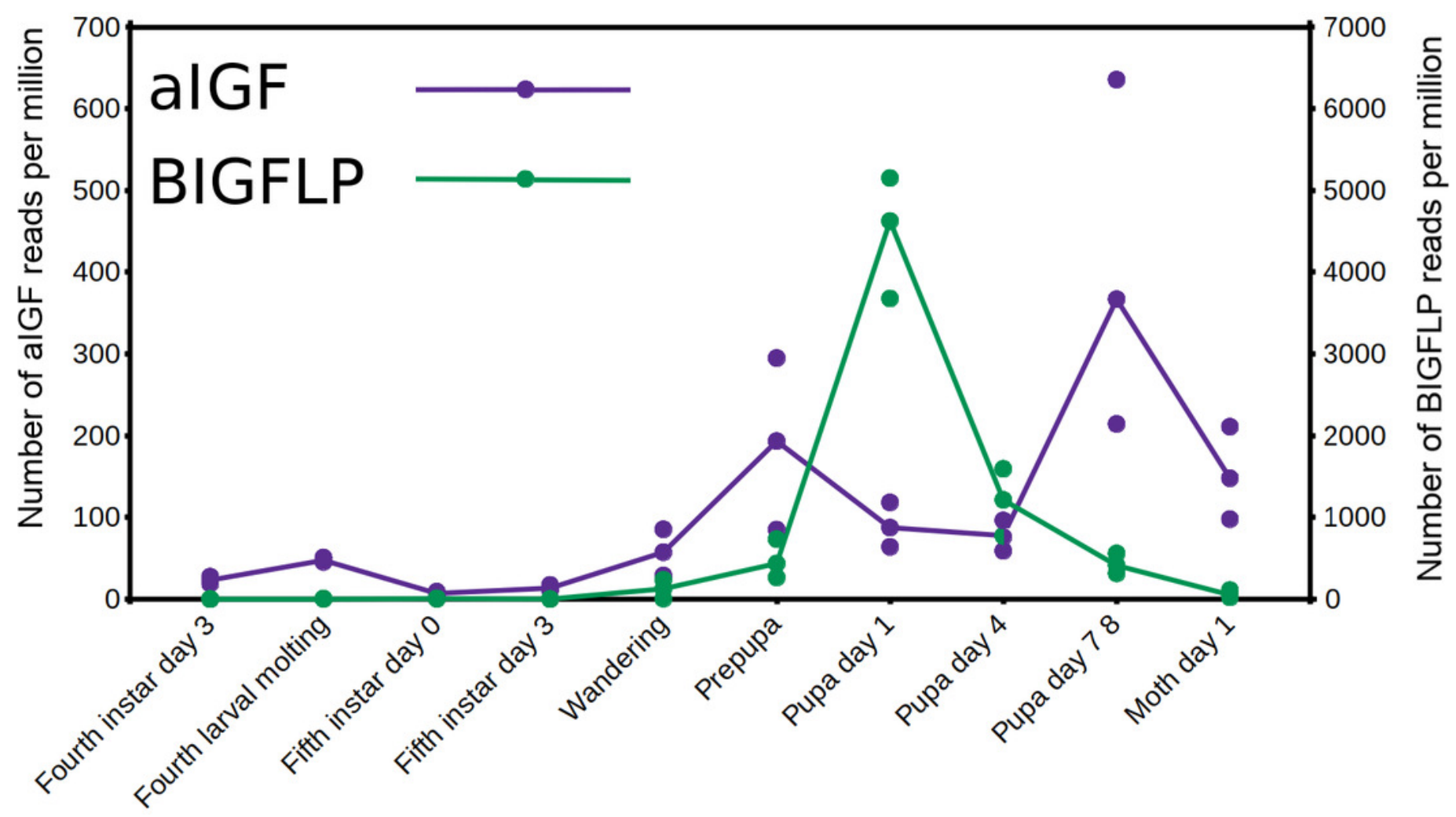


Figure 7

Differential expression of Bombyx alGF alternative splice forms.

Counts of reads specific for the long isoform of alGF were plotted agains the total number of alGF reads in all Bombyx SRAs $(n=253)$. Samples with high total alGF counts show different levels of expression of the long isoform. Identification of some of the salient samples in this figure is provided in Fig. S5.

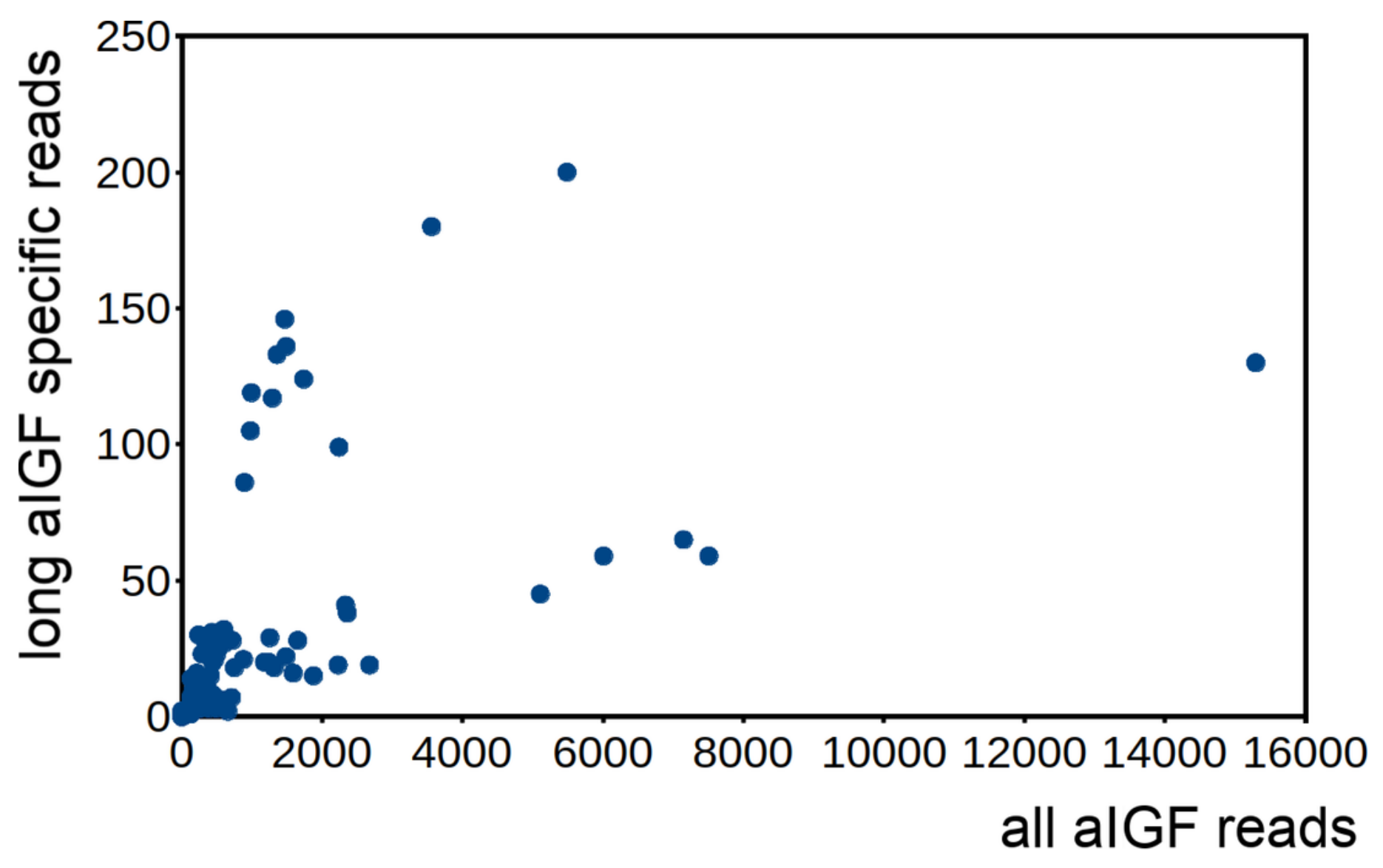




\section{Figure 8}

\section{Evolution of the insect alGF gene.}

Schematic organization of insect alGF genes in relation to their place on a simplified phylogenetic tree. The archetype of the insect alGF gene consists of four coding exons. The first codes for the signal peptide (orange brown color) and the B-chain and part of the Cpeptide, the second codes for the remainder of the C-peptide and the A-chain. The third coding exon codes for the first part of the C-terminal extension and has in the middle an alternative splice site allowing alternative splicing of the arginine rich sequene (in red). The last coding exon (yellow) codes for final part of the C-terminal extension that contains the $\mathrm{GTVX}_{1} \mathrm{PX}_{2}(\mathrm{~F} / \mathrm{Y})$ consensus sequence. Diptera have lost the third coding exon and the Eremoneura have also lost the fourth coding exon. Sequence comparison of the alLGF precursors from Dasypogon, Hermetia, Condylostylus and Platypeza are very similar, except for the loss of the last part (Fig. S6). The structures of the Blattella, Apis, Tribolium and Bombyx genes are from Fig. 5 and those of the Oncopeltus and Aedes genes from Fig. S3. The Timema, Hermetia, Dasypogon, Ceratitis, Drosophila and Glossina genes were produced in the same fashion. The Condylostylus gene could only partially constructed from genome and transcriptome SRAs. The Platypeza gene has been made transclucent, as is only inferred; it is on a transcript (GCGU01007956.1) and assumes that its structure is identical to those of its closest relatives. 


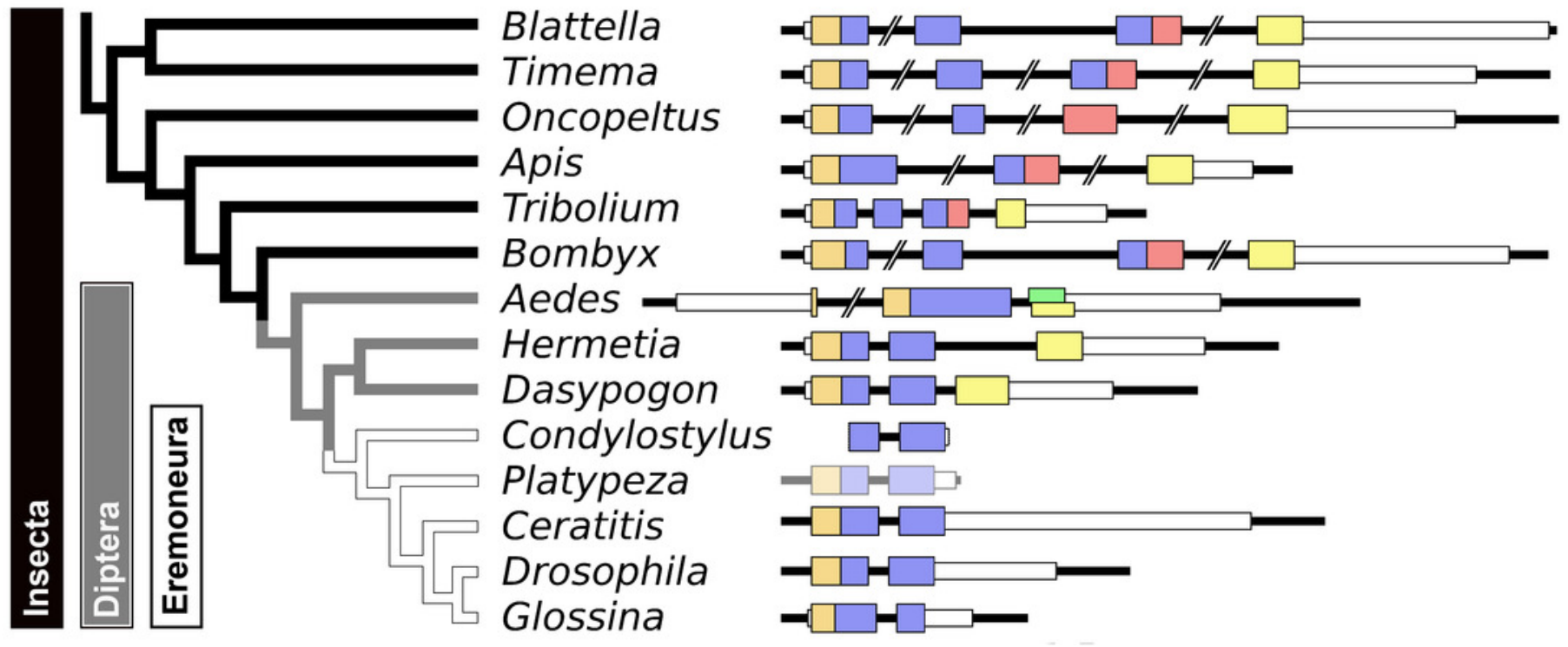




\section{Figure 9}

Arthropod relaxin sequence alignment.

Note how the relaxin propeptides are much better conserved than the either the gonadulins or the alGFs. Also not that the exception is the single decapod relaxin that has also an additional cysteine residue. This is not a sequencing or other technical error, as the same residue is also found in several others decapods from different decapod orders (Fig. S7). Cysteine residues are highlighted in red, other conserved amino acid residues in black and conservative substitutions in grey. Sequences are provided in Suppl. Spreadsheet 1 and from Veenstra (2020). 
Drosophila Anopheles Athalia

Timema

Blattella

Leptinotarsa Nephrops

Mesobuthus-1 Mesobuthus-2 Parasteatoda Tetranychus

Drosophila Anopheles Athalia Timema Blattella Leptinotarsa Nephrops Mesobuthus-1 Mesobuthus-2 Parasteatoda Tetranychus

Drosophila Anopheles Athalia

Timema

Blattella

Leptinotarsa Nephrops Mesobuthus-1 Mesobuthus-2 Parasteatoda Tetranychus

Drosophila Anopheles Athalia Timema Blattella Leptinotarsa Nephrops Mesobuthus-1 Mesobuthus-2 Parasteatoda Tetranychus

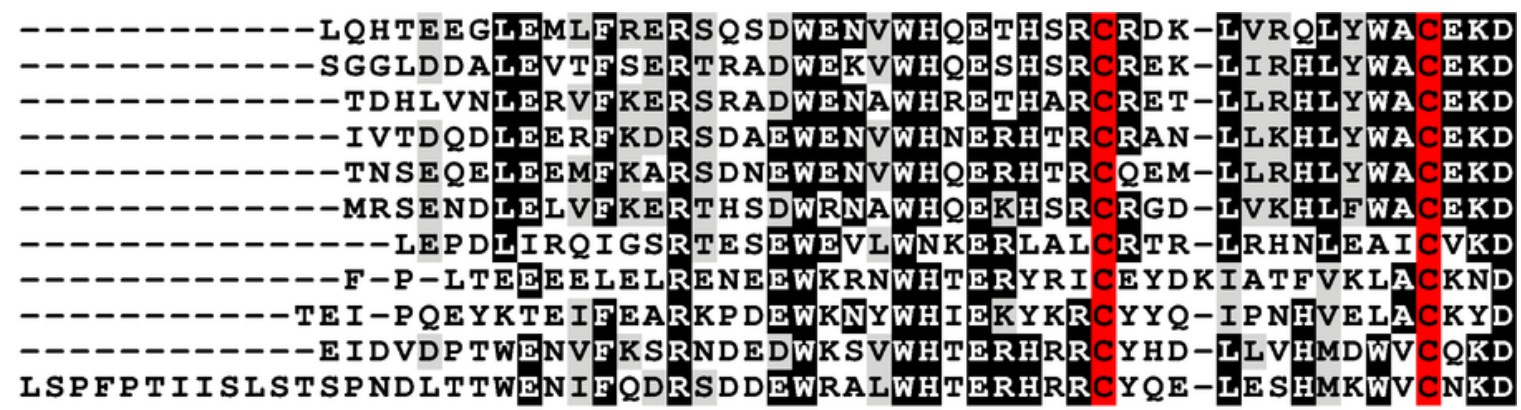

IYRLTRRNKKRTGNDE---AWIKK------- - - - - - - - - - - - - - - - - TT TEPD

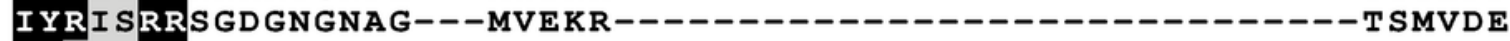

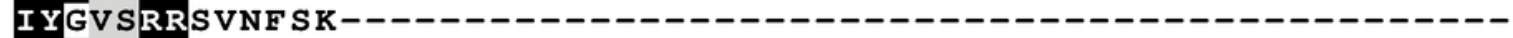
IYRLSRRNDQHS-

I YRISRRNGFODLOL--- O-

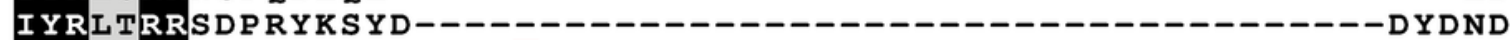
VYRRSITSPNHHHIKRSTDICLKVHDSDGEGDIRDKGAVSVNLPTATIEITPSSPDTGQH IYKINNEE---LQNQNT-

IYKVPVDKREESSKPIL

I YAVKRDKRDTEPFID-

IYKVKKSDSEIETVSS

GS----TWL-HVNYANMFI----RSRRS--DGN---TPSISNEC GP LVP YPWA I DREVAYAFI----RTRRT GKRRS---GGS I TAE - P P P P PWVS GW-RAKEML--- -RYRRDLRRRSPAAVAS I TQE --HVGSPFVSVV-EARVFL----RSRRDRKRRSAA-GGS I TDE KYNPKYPFLSVV-EARVFL----RNRRGRRRRS-A-EPS I TDE D I EVDFPWKSPR-RAKR IL----RFRRS IDRRS---GSS I TNE NIYTRSPF LSVQ-QANLFVTTWVGGRRGGHYRRRRQS SS I TAE - - - FNNEVKKDKYIPISLAYSFGIKK-TNP I LKRRKRGI TQE - - - F KRFQKPDEYLPIYIIHGFGTKKRNG-RKRRGTGGIVQE ------------EMQ--AHQF L GRHRKRS GAHHALVKRGII DE FEGRHYDAF ISKE---RALNLLG-----QTATSVRRKRGII DEC

-TKAGCTWEEYAEY -TRTGCTWEEYAEY -GGPGCTWEEYAEY QASGGCTWEEYAEY CHNSAGCTWEEYAEY -KSTGCTWEEYAEY -TTVGCTWEEYAEY ENTAGCYWEELAEY EKSNGCSWEEYAEY HGNAGCSWEEYAEY HGANGCSWEEYAEYC

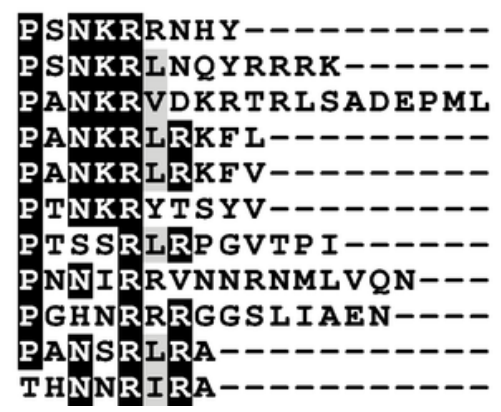


Figure 10

Synteny of arthropod ilp genes.

Schematic representation of relaxin, gonadulin and aIGF genes in three insect and two spider species. Genbank accession numbers are indicated below the species name. Arrowheads indicate the direction of transcription. The numbers in Kbp indicate the distances between the coding regions of neighboring genes.

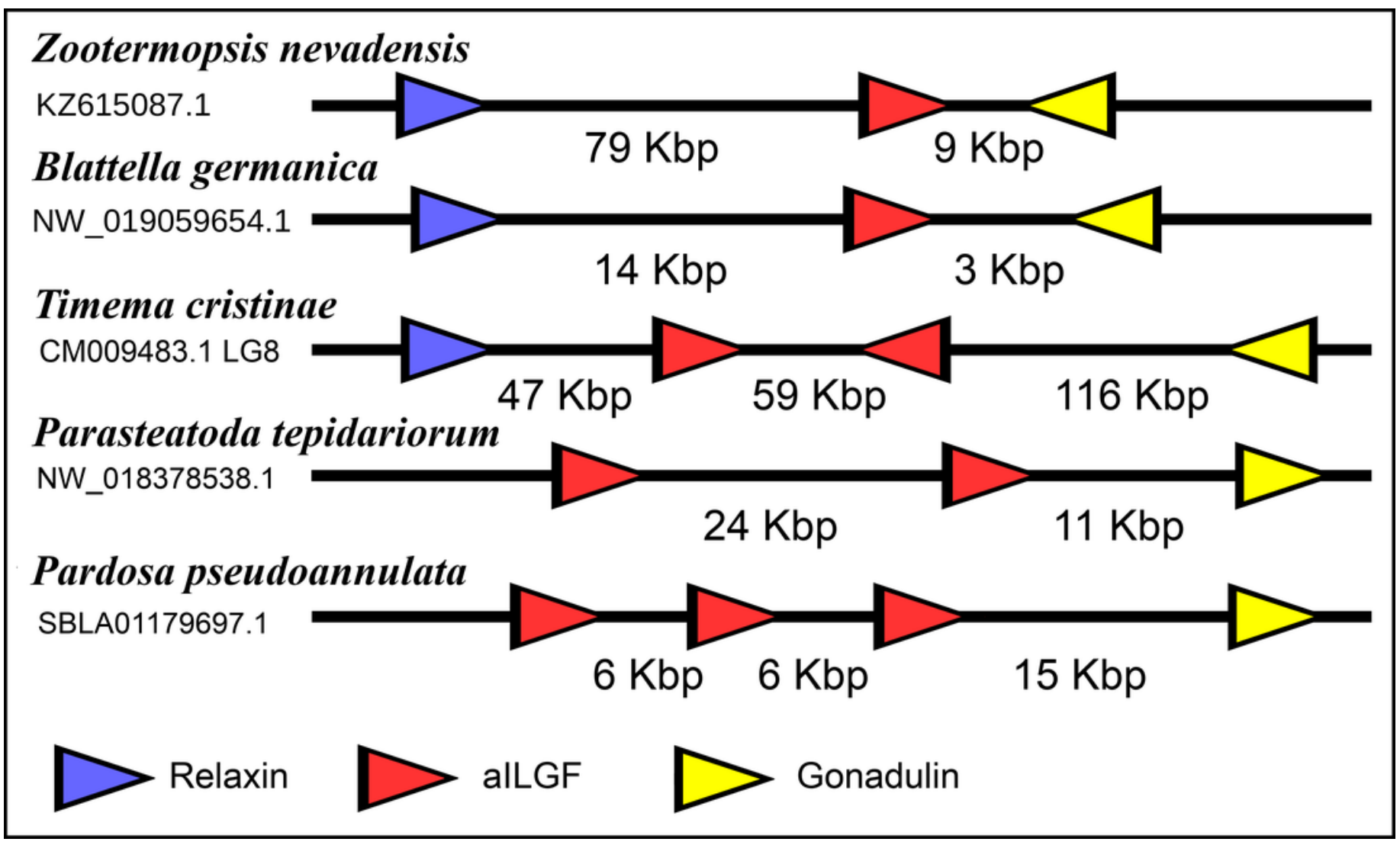




\section{Figure 11}

Phylogenetic tree of arthropod insulin RTKs.

Phylogenetic tree of various arthropod RTKs. Note that the decapods, chelicerates and insect RTKs evolved independently. Only branch probabilities of more than 0.900 have been indicated. Sequences are from (Veenstra, 2020) and others provided in Supp. Spreadsheet 1. 


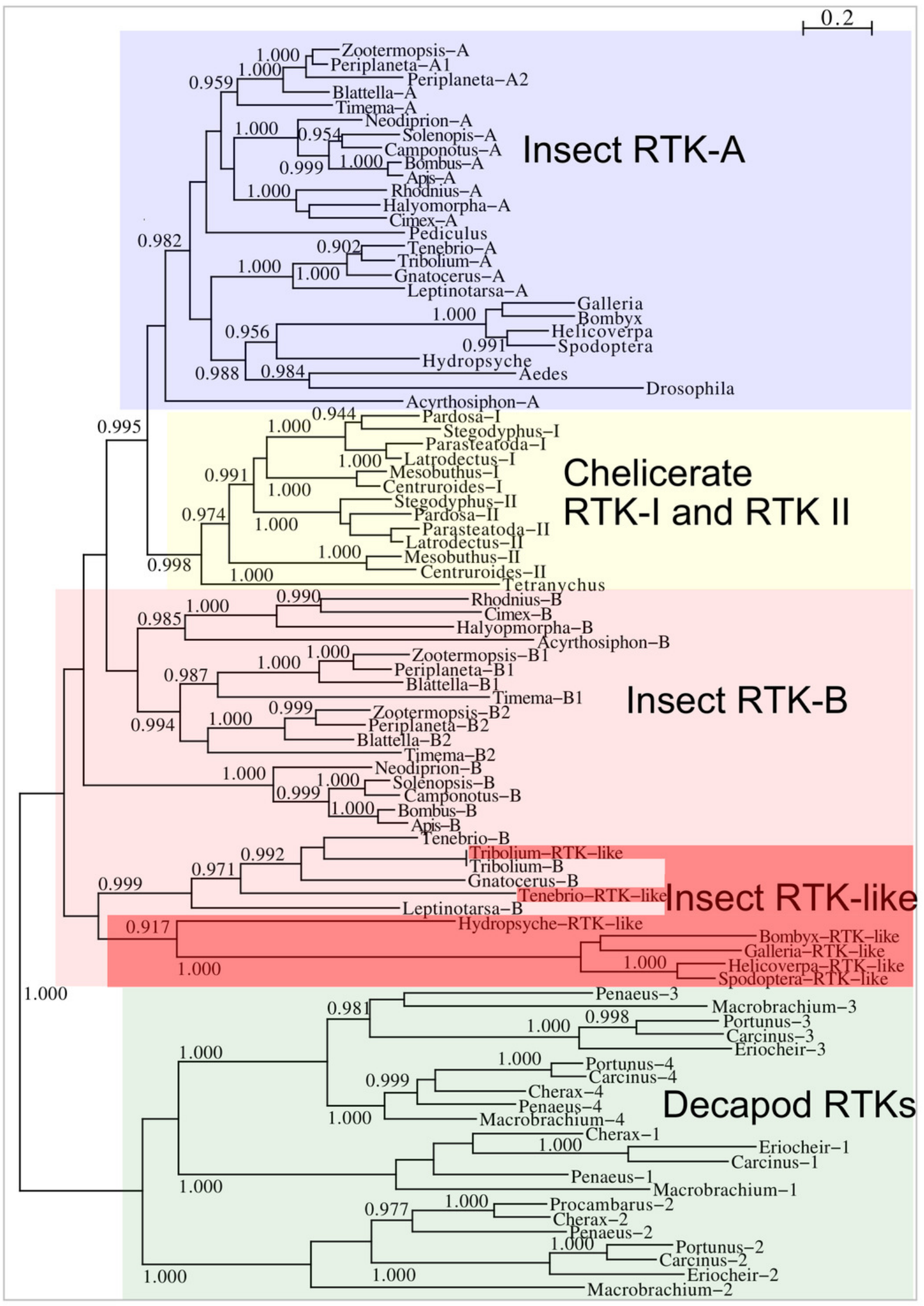




\section{Figure 12}

Phylogenetic tree of putative arthropod insulin GPCRs.

Phylogenetic tree based exclusively on the transmembrane regions of various decapod LGRs that might function as receptors for insulin-related peptides. Only branch probabilities of more than 0.900 have been indicated. Sequences are from (Veenstra, 2020) and others provided in Supp. Spreadsheet 1. 


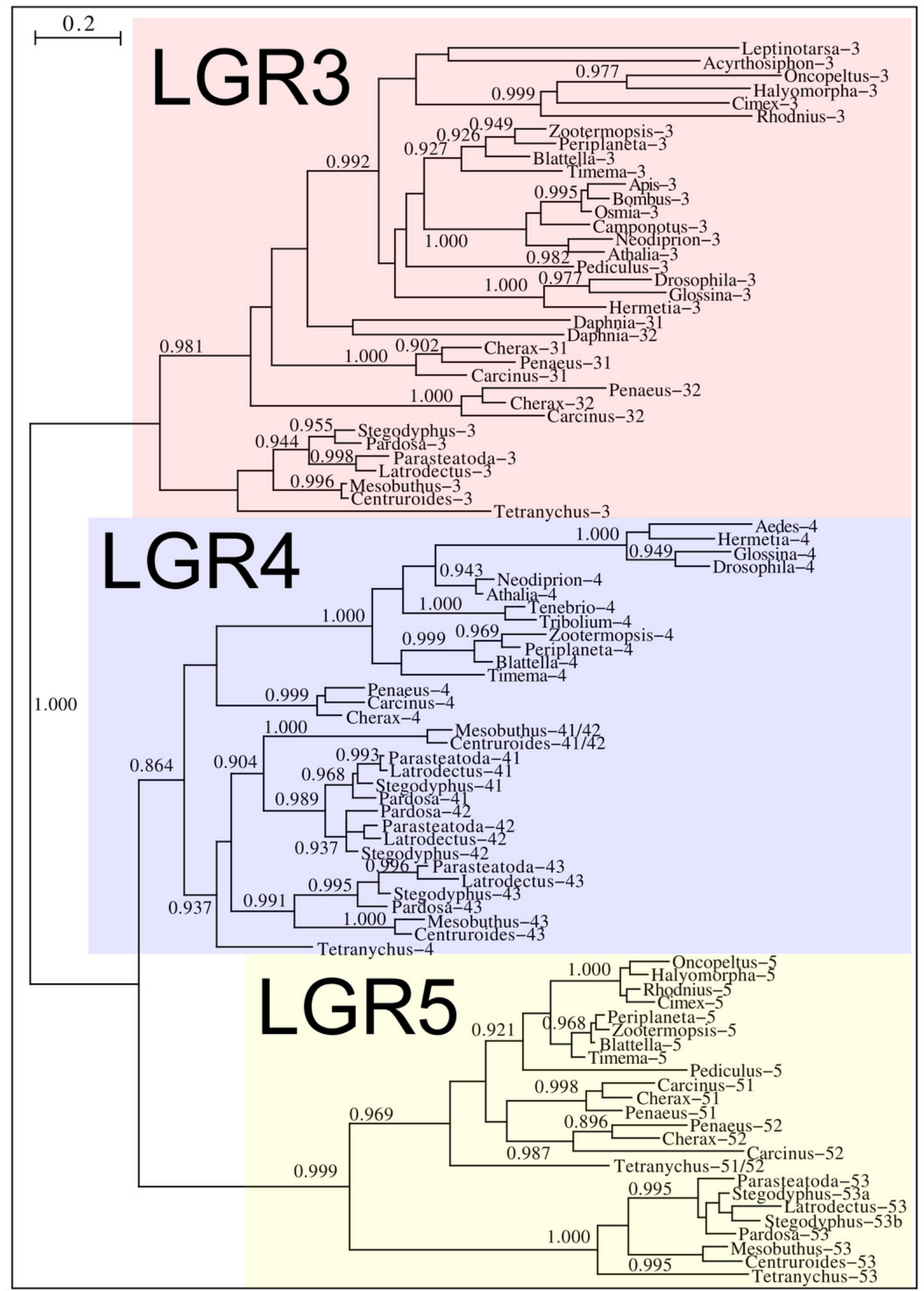




\section{Table $\mathbf{1}$ (on next page)}

Gonadulin expression.

Numbers are the number of gonadulin half reads per million in one or more transcriptome SRAs. This is a selection of the data from Suppl. Spreadsheet 2. 
Table1. Gonadulin expression.

Species

Blattella germanica

Rhodnius prolixus

Apis mellifera

Timema cristinae

0.20

3.00

0.20

61.60

96.70

59.00

7.10

4.10

Steatoda grossa

0.00

7.10

5.90

3.30

Parasteatoda tepidariorum

2.00

0.00

0.00

\section{Tissue/organ}

Male heads

Female gonads and fat body

Male gonads and fat body

Non-fecundated eggs

Head

Testis

Ovary

Ovary

Testis

CNS

Antenna

Ovary of virgin queen

Ovary of normal egg-laying queen

Ovary of normal egg-laying inhibted queen

Ovary of normal egg-laying recovered queen

Antenna

Second thoracic ganglion

Cephalothorax

Ovary with eggs

Minor ampullate silk glands

Tubuliform silk glands

Ovary from SRR1824489

Ovary from SRR8755633

Ovary from SRR8755634

Numbers are the number of gonadulin half reads per million in one or more transcriptome SRAs. This is a selection of the data from Suppl. Spreadsheet 2. 